\title{
Ozonolysis of $\alpha$-phellandrene - Part 1: Gas- and particle-phase characterisation
}

\author{
Felix A. Mackenzie-Rae ${ }^{1}$, Tengyu Liu ${ }^{2,3, a}$, Wei Deng ${ }^{2,3}$, Sandra M. Saunders ${ }^{1}$, Zheng Fang ${ }^{2,3}$, Yanli Zhang ${ }^{2,4}$, and \\ Xinming Wang ${ }^{2,4}$ \\ ${ }^{1}$ School of Molecular Sciences, The University of Western Australia, Crawley WA 6009, Australia \\ ${ }^{2}$ State Key Laboratory of Organic Geochemistry and Guangdong Key Laboratory of Environmental Protection and Resources \\ Utilization, Guangzhou Institute of Geochemistry, Chinese Academy of Sciences, Guangzhou 510640, China \\ ${ }^{3}$ University of Chinese Academy of Sciences, Beijing 100049, China \\ ${ }^{4}$ Center for Excellence in Regional Atmospheric Environment, Institute of Urban Environment, \\ Chinese Academy of Sciences, Xiamen 361021, China \\ ${ }^{a}$ now at: School of Energy and Environment, City University of Hong Kong, Hong Kong, China
}

Correspondence to: X. Wang (wangxm@gig.ac.cn)

Received: 10 January 2017 - Discussion started: 10 January 2017

Revised: 18 April 2017 - Accepted: 1 May 2017 - Published: 6 June 2017

\begin{abstract}
The ozonolysis of $\alpha$-phellandrene, a highly reactive conjugated monoterpene largely emitted by Eucalypt species, is characterised in detail for the first time using a smog chamber at the Guangzhou Institute of Geochemistry, Chinese Academy of Sciences. Gas-phase species were monitored by a proton-transfer-reaction time-of-flight mass spectrometer (PTR-TOF), with yields from a large number of products obtained, including formaldehyde (5$9 \%$ ), acetaldehyde $(0.2-8 \%)$, glyoxal (6-23\%), methyl glyoxal (2-9\%), formic acid (22-37\%) and acetic acid (9-22\%). Higher $\mathrm{m} / \mathrm{z}$ second-generation oxidation products were also observed, with products tentatively identified according to a constructed degradation mechanism. $\mathrm{OH}$ yields from $\alpha$-phellandrene and its first-generation products were found to be $35 \pm 12$ and $15 \pm 7 \%$, respectively, indicative of prominent hydroperoxide channels. An average first-generation rate coefficient was determined as $1.0 \pm 0.7 \times 10^{-16} \mathrm{~cm}^{3}$ molecule ${ }^{-1} \mathrm{~s}^{-1}$ at $298 \mathrm{~K}$, showing ozonolysis as a dominant loss process for both $\alpha$ phellandrene and its first-generation products in the atmosphere. Endocyclic conjugation in $\alpha$-phellandrene was also found to be conducive to the formation of highly condensible products with a large fraction of the carbon mass partitioning into the aerosol phase, which was monitored with a scanning mobility particle sizer (SMPS) and a high-resolution timeof-flight aerosol mass spectrometer (AMS). Nucleation was
\end{abstract}

observed almost instantaneously upon ozonolysis, indicating the rapid formation of extremely low-volatility compounds. Particle nucleation was found to be suppressed by the addition of either $\mathrm{NO}_{2}$ or a Criegee scavenger, with it being proposed that stabilised Criegee intermediates are important for new particle formation in the system. Aerosol yields ranged from 25 to $174 \%$ depending on mass loadings, with both first- and second-generation products identified as large contributors to the aerosol mass. In short, with a high chemical reactivity and aerosol-forming propensity, $\alpha$-phellandrene is expected to have an immediate impact on the local environment to which it is emitted, with ozonolysis likely to be an important contributor to the significant blue haze and frequent nocturnal nucleation events observed over Eucalypt forests.

\section{Introduction}

Biogenic sources dominate the global emission budget of volatile organic compounds into the atmosphere, with monoterpenes accounting for a significant fraction of nonmethane hydrocarbons emitted (Guenther et al., 1995; Schurgers et al., 2009; Guenther et al., 2012; Lathière et al., 2006; Sindelarova et al., 2014). Considering source strength, estimated to be $30-127 \mathrm{TgC}$ year $^{-1}$, along with high chemi- 
cal reactivity (Calvert et al., 2000; Atkinson and Arey, 2003), monoterpenes are thought to play an important role in the chemistry of the atmosphere, influencing its oxidative capacity, the tropospheric ozone budget and producing secondary organic aerosol (SOA) with impacts on both health and climate (Hoffmann et al., 1997; Griffin et al., 1999a; Chung and Seinfeld, 2002; Hallquist et al., 2009; Pye et al., 2010). Indeed, the ozonolysis of monoterpenes is thought to be one of the major sources of organic SOA in the atmosphere (Griffin et al., 1999b; Ortega et al., 2012).

Consequently, the gas-phase reaction of ozone with monoterpenes has been the focus of numerous studies, both experimental, with a focus on gas-phase kinetics and particle formation, properties and composition (e.g. Bateman et al., 2009; Berndt et al., 2003; Griffin et al., 1999a; Herrmann et al., 2010; Lee et al., 2006; Ma et al., 2007; Pathak et al., 2007; Saathoff et al., 2009; Shilling et al., 2008, 2009; Walser et al., 2008), and theoretical, utilising state-of-the-art computational methods (Zhang and Zhang, 2005; Nguyen et al., 2009). Collectively, research has come a long way to understand the mechanism and product distributions of monoterpene ozonolysis and provided important insights into SOA precursors and production. Accurate chemical mechanisms for the reaction of specific monoterpenes with ozone have since been developed (Camredon et al., 2010; Jenkin, 2004; Leungsakul et al., 2005), whilst more general parameterisations for gas-phase reactions (Jenkin et al., 1997; Saunders et al., 2003) and SOA formation (Odum et al., 1996; Donahue et al., 2006; Stanier et al., 2008) have been implemented into chemical transport models.

Ozonolysis is generally agreed to occur through a concerted cycloaddition of ozone to the olefin bond, forming a 1,2,3-trioxolane intermediate species referred to as a primary ozonide (POZ) (Calvert et al., 2000; Johnson and Marston, 2008). Addition of ozone is highly exothermic with excess energy retained in the POZ structure, resulting in rapid decomposition through homolytic cleavage of the $\mathrm{C}-\mathrm{C}$ and one of the $\mathrm{O}-\mathrm{O}$ bonds, which forms, in the case of asymmetrically substituted alkenes, a pair of products containing a carbonyl and a reactive Criegee intermediate (CI). Sufficient vibrational and rotational excitation exists in the $\mathrm{CI}$ to permit further unimolecular decomposition which typically occurs through one of two channels; firstly, excited CIs can cyclise to a dioxirane, which then decomposes to a carboxylic acid, ester or lactone, depending on neighbouring substituents, in what is known as the ester or "hot" acid channel, or secondly, when available, excited CIs can isomerise via a 1,5hydrogen shift to form a vinyl hydroperoxide, which subsequently decomposes into a vinoxy radical and a hydroxyl radical in what is known as the hydroperoxide channel. Alternatively, excited CIs can be collisionally stabilised such that bimolecular reactions with trace species (e.g. $\mathrm{H}_{2} \mathrm{O}, \mathrm{NO}_{2}, \mathrm{CO}$, aldehydes, acids) become important (Johnson and Marston, 2008). The relative prevalence of these competing channels is strongly linked to the structure and conformation of the CI
(Vereecken et al., 2015), with the various mechanistic pathways summarised in Fig. 1.

When considered as a whole, research shows significant variability in gas-phase ozonolysis products and SOA yields between different monoterpenes due to their structural differences, highlighting the unique impact different monoterpenes can have on regional atmospheric chemistry. It is therefore important that individual monoterpene variability be accounted for in developing accurate gas- and particlephase models. Nonetheless, current literature has predominantly focused on a small number of the more commonly emitted monoterpenes (e.g. $\alpha$-pinene, $\beta$-pinene, limonene). One monoterpene for which relatively little is known is $\alpha$ phellandrene (structure provided in Fig. 1). One of the most reactive monoterpenes, $\alpha$-phellandrene has been identified as a major constituent of extracts (Li et al., 1995; Brophy and Southwell, 2002; Pavlova et al., 2015; Maghsoodlou et al., 2015) and in emissions (He et al., 2000; Maleknia et al., 2009) from various Eucalypt species, the world's most widely planted hardwood tree (Myburg et al., 2014). During day-to-day activities and processes, Eucalypts, such as Eucalyptus microtheca, Eucalyptus viminalis and Eucalyptus dives, emit $\alpha$-phellandrene into the atmosphere, with $\alpha$ phellandrene likely contributing to the intense and frequent particle nucleation events observed over Eucalypt forests - a phenomenon already believed to be caused by monoterpene oxidation (Suni et al., 2008; Lee et al., 2008; Ortega et al., $2009,2012)$. In the indoor environment, $\alpha$-phellandrene can be found as an additive to household cleaning products, detergents and air fresheners (e.g. Eucalypt-themed products), with the European EPHECT project reporting $\alpha$ phellandrene at a concentration of $16.7 \mu \mathrm{g} \mathrm{m}^{-3}$ in a study of a passive air freshener in a $1 \mathrm{~m}^{3}$ room after $5 \mathrm{~h}$ (Stranger, 2013). Maisey et al. (2013) reported similar maximum concentrations of $\alpha$-phellandrene in Australian dwellings.

The rate constant of $\alpha$-phellandrene with ozone has been measured in a number of studies with results spanning an order of magnitude (Grimsrud et al., 1975; Atkinson et al., 1990; Shu and Atkinson, 1994), with a rate constant of $3.0 \times$ $10^{-15}( \pm 35 \%) \mathrm{cm}^{3}$ molecule $\mathrm{s}^{-1} \mathrm{~s}^{-1}$ favoured (Calvert et al., 2000). High chemical reactivity likely makes ozonolysis a dominant loss process for $\alpha$-phellandrene in the atmosphere; however, experimental information regarding reaction products is limited to $\mathrm{OH}$ radical yields, measured by Herrmann et al. (2010) to be 26-31 and 8-11\% for the ozonolysis of the two double bonds, and acetone yields, which were reported by Reissell et al. (1999) to be minor $(<2 \%)$. Recently, the reaction mechanism was investigated theoretically for the first time by Mackenzie-Rae et al. (2016), who mapped the potential energy surface to first-generation products. A basic overview of the reaction pathways is provided in Fig. 1, with a comprehensive discussion of the reaction mechanism of $\alpha$-phellandrene with ozone based on findings of MackenzieRae et al. (2016) pertinent to this study provided in the Supplement (Sect. S1). 


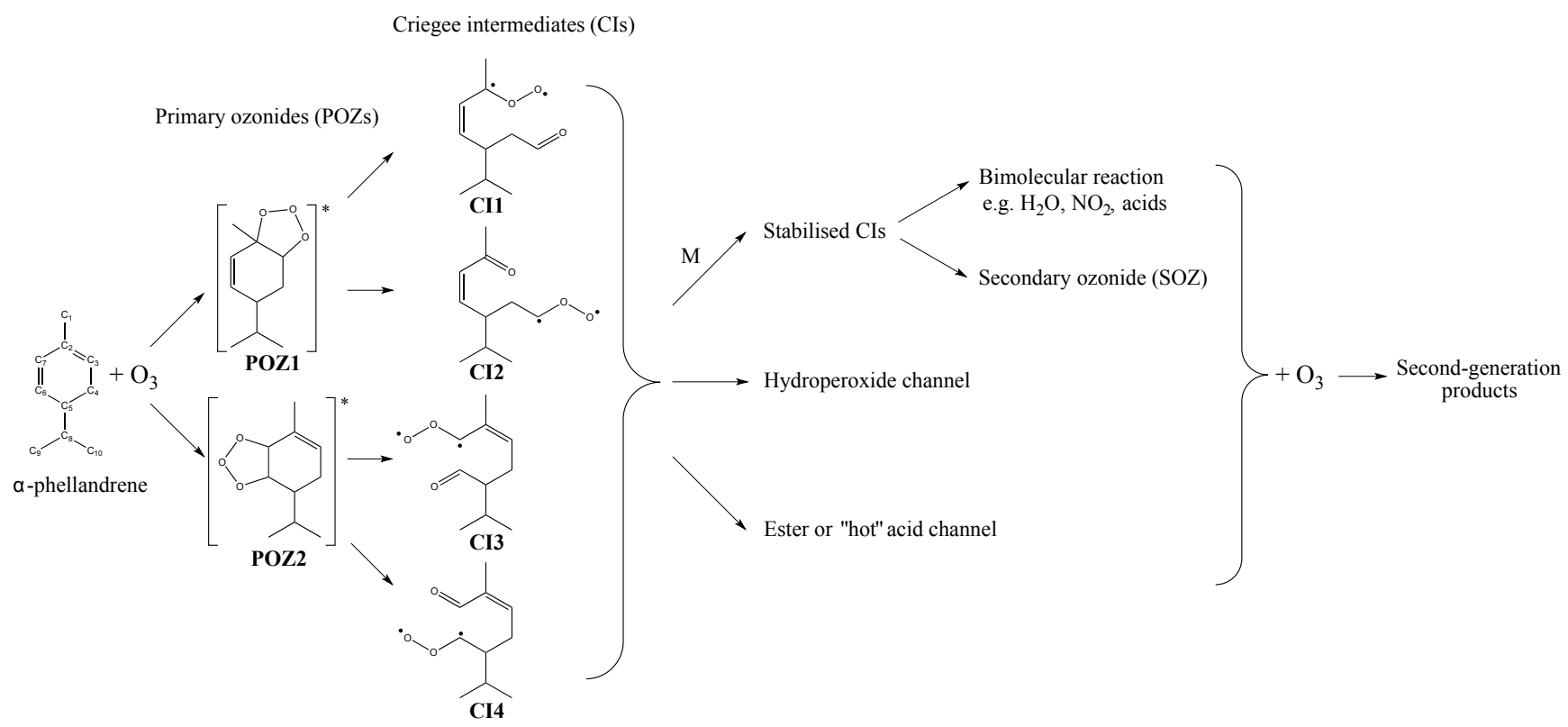

Figure 1. Simplified mechanism showing reaction processes involved during ozone addition to $\alpha$-phellandrene within conventional frameworks (adapted from Mackenzie-Rae et al., 2016). Carbon labels on $\alpha$-phellandrene are referred to in the main text.

This study aims to experimentally characterise the reaction of $\alpha$-phellandrene with ozone in detail for the first time by exploring and characterising both the gaseous and particle phases, with the impact of Criegee scavengers and $\mathrm{NO}_{2}$ on the system addressed. In doing so, the impact of a highly reactive and potentially important monoterpene will be parameterised.

\section{Materials and method}

\subsection{Experimental set-up and procedure}

A total of 11 dark $\alpha$-phellandrene ozonolysis experiments were conducted using the indoor smog chamber facility at the Guangzhou Institute of Geochemistry, Chinese Academy of Sciences (GIG-CAS). A complete description of the facility and chamber setup is given in Wang et al. (2014). Briefly, the GIG-CAS smog chamber consists of a $30 \mathrm{~m}^{3} \mathrm{flu}-$ orinated ethylene propylene (FEP) reactor housed inside a temperature-controlled room. The reactor was flushed with purified dry air for at least $48 \mathrm{~h}$ prior to each experiment, until no residual hydrocarbons, $\mathrm{O}_{3}, \mathrm{NO}_{x}$ or particles were detected, with the impact of off-gassing of radicals from the reactor walls during experiments under the dark, dry conditions considered negligible (Wang et al., 2014). Two Tefloncoated fans located inside the reactor ensure rapid homogenisation of introduced species. Liquid reactants were vaporised via injection into a heating system similar to that of gas chromatography, before being carried by nitrogen gas through FEP Teflon lines into the reactor. Ozone was generated using a commercial ozone generator (VMUS-4, Azco
Industries Ltd.), with pure oxygen feed gas. Initial mixing ratios of the reactants varied between 10 and $175 \mathrm{ppb}$ for $\alpha$ phellandrene (Aldrich Chemical Company, Inc., USA) and between 56 and $500 \mathrm{ppb}$ for $\mathrm{O}_{3} . \alpha$-Phellandrene was injected prior to admission of $\mathrm{O}_{3}$ into the chamber, with $\mathrm{O}_{3}$ added through two separate additions in experiments 7 and 10 to facilitate the identification of detected species as either first- or second-generation products. Anhydrous cyclohexane (Sigma-Aldrich, $99.5 \%$ ) was added in sufficient quantity in all but two experiments to scavenge $>95 \%$ of $\mathrm{OH}$ radicals (Aschmann et al., 1996; Herrmann et al., 2010), with the remaining experiments used to asses the impact of cyclohexane's inclusion. Formic acid (J\&K Scientific Ltd., $98 \%$ ) was added to experiments 6 and 7 as a stabilised Criegee intermediate (sCI) scavenger to better understand the impact of sCIs on gas-phase species distribution and, importantly, particlephase formation and growth, for which it has been identified as a significant precursor (Bonn et al., 2002; Bateman et al., 2009; Sakamoto et al., 2013; Wang et al., 2016). Prior to $\mathrm{O}_{3}$ addition in experiment $11,385 \mathrm{ppb}$ of $\mathrm{NO}_{2}$ was added through a septum installed in one of the injection ports using a gas-tight syringe, with the inclusion providing an alternative representation of tropospheric nocturnal chemistry in a polluted environment. All experiments had $2.5 \mu \mathrm{L}$ of acetonitrile injected as a dilution tracer, with the top frame of the reactor periodically lowered to maintain a positive pressure differential inside the reactor. Experimental run times ranged from 205 to $305 \mathrm{~min}$, with a final reactor volume typically between 6 and $8 \mathrm{~m}^{3}$. The starting conditions for each experiment are listed in Table 1 . The high reactivity of $\alpha$ phellandrene towards ozone results in reaction half lives that 
Table 1. Starting conditions for $\alpha$-phellandrene chamber ozonolysis experiments.

\begin{tabular}{|c|c|c|c|c|c|}
\hline No. & $\begin{array}{r}\text { Temperature } \\
(\mathrm{K})\end{array}$ & $\begin{array}{r}\text { Relative humidity } \\
(\%)\end{array}$ & $\begin{array}{r}\alpha \text {-phellandrene } \\
(\mathrm{ppb})\end{array}$ & $\begin{array}{r}\mathrm{O}_{3} \\
(\mathrm{ppb})\end{array}$ & Additives $^{\mathrm{a}}$ \\
\hline 1 & $297.1 \pm 0.4$ & $2.5 \pm 0.6$ & $19 \pm 7$ & $>259$ & Cyclohexane \\
\hline 2 & $297.5 \pm 0.5$ & $2.1 \pm 0.7$ & $10 \pm 4$ & $>86$ & Cyclohexane \\
\hline 3 & $297.2 \pm 0.2$ & $2.3 \pm 0.6$ & $21 \pm 8$ & $>83$ & Cyclohexane \\
\hline 4 & $297.4 \pm 0.5$ & $2.2 \pm 0.9$ & $32 \pm 13$ & $>193$ & Cyclohexane \\
\hline 5 & $297.6 \pm 0.7$ & $1.8 \pm 0.4$ & $29 \pm 11$ & $>114$ & Cyclohexane \\
\hline 6 & $298.0 \pm 0.3$ & $1.6 \pm 0.1$ & $16 \pm 6$ & $>470$ & $\begin{array}{l}\text { Cyclohexane } \\
\text { Formic acid }\end{array}$ \\
\hline 7 & $298.0 \pm 0.1$ & $1.9 \pm 0.2$ & $19 \pm 8$ & $>499$ & $\begin{array}{l}\text { Cyclohexane } \\
\text { Formic acid }^{\text {b }}\end{array}$ \\
\hline 8 & $298.7 \pm 0.6$ & $5.2 \pm 0.2$ & $61 \pm 24$ & $>56$ & Cyclohexane \\
\hline 9 & $298.5 \pm 0.4$ & $4.9 \pm 0.4$ & $67 \pm 27$ & $>101$ & - \\
\hline 10 & $298.2 \pm 0.5$ & $4.8 \pm 0.3$ & $175 \pm 69$ & $>174$ & Cyclohexane \\
\hline 11 & $298.1 \pm 0.4$ & $4.5 \pm 0.2$ & $88 \pm 35$ & $>132$ & $\mathrm{NO}_{2}{ }^{\mathrm{c}}$ \\
\hline
\end{tabular}

a All experiments had acetonitrile $(2.5 \mu \mathrm{L})$ added as a dilution tracer.

$\mathrm{b} 800 \pm 80 \mathrm{ppb}$ added prior to starting experiment.

c $385 \pm 5 \mathrm{ppb}$ added prior to starting experiment.

are similar to the mixing time of the reactor. Consequently only a lower bound of the ozone concentration is known.

\subsection{Characterisation of gas and particle phases}

Volatile organic compounds (VOCs) were measured online with a commercial proton-transfer-reaction time-offlight mass spectrometer (PTR-TOF 2000, Ionicon Analytik $\mathrm{GmbH}$, Austria) (Jordan et al., 2009; Graus et al., 2010), using $\mathrm{H}_{3} \mathrm{O}^{+}$reagent ions. For data collected in the first seven experiments in Table 1, the PTR-TOF drift tube was operated at $2.2 \mathrm{mbar}$ and $60^{\circ} \mathrm{C}$, with a drift tube field of $600 \mathrm{~V} \mathrm{~cm}^{-1}(E / N=136 \mathrm{Td})$. Significant fragmentation was observed under this regime, with a drift tube voltage of $484 \mathrm{~V} \mathrm{~cm}^{-1}(E / N=112 \mathrm{Td})$ found to be optimal (Supplement Sect. S3). The refined operating conditions were then used for experiments 8-11. PTR-TOF spectra were collected at a time resolution of $2 \mathrm{~s}$. Data were processed using the PTR-TOF data analyser (Müller et al., 2013), with 30 spectra averaged to improve counts of trace species. A generic $\mathrm{H}_{3} \mathrm{O}^{+}$rate constant of $2 \times 10^{-9} \mathrm{~cm}^{3} \mathrm{~s}^{-1}$ was used for conversion into ppb, except for those species where experimental or theoretical data exist (Cappellin et al., 2012; Tani, 2013).

Gas-phase $\mathrm{O}_{3}$ and $\mathrm{NO}_{x}$ were measured online using dedicated monitors (EC9810 and 9841T, Ecotech, Australia), which were calibrated regularly using a Thermo Scientific model 146i multi-gas calibrator unit. In all experiments, excluding experiment 11 where it is added, $\mathrm{NO}_{x}$ concentrations were negligible $(<1 \mathrm{ppb})$. The $\mathrm{O}_{3}$ analyser experienced significant interference (had a false bias) from $\alpha$-phellandrene, which was corrected for using PTR-TOF measurements.

Particle number size distributions were measured online with a scanning mobility particle sizer (SMPS; TSI Inc., USA) (Wang and Flagan, 1990), consisting of an electro- static classifier (TSI 3080) fitted with a TSI 3081 differential mobility analyser (DMA) and condensation particle counter (CPC, TSI 3775). Sheath and aerosol flow rates were 3.0 and $0.3 \mathrm{~L} \mathrm{~min}^{-1}$, respectively, with voltage inside the DMA varied exponentially from -10 to $-9950 \mathrm{~V}$ every $240 \mathrm{~s}$ to provide a mobility spectrum over particle diameters $14-750 \mathrm{~nm}$. Higher moment size distributions were calculated by assuming spherical particles (Wiedensohler et al., 2012).

A high-resolution time-of-flight aerosol mass spectrometer (AMS; Aerodyne Research Incorporated, USA) was used to measure particle chemical composition in real time (Jayne et al., 2000; DeCarlo et al., 2006). The AMS was operated in the high-sensitivity $\mathrm{V}$ mode and high-resolution $\mathrm{W}$ mode, switching between modes every $2 \mathrm{~min}$. AMS data were analysed in Igor Pro 6.2 (Wavemetrics) using the ToF-AMS data analysis toolkits Peak Integration by Key Analysis (PIKA) and Sequential Igor Data Retrieval (SQUIRREL). Updates were made to the fragmentation table following a similar method to Chen et al. (2011), with a detailed discussion provided in the Supplement (Sect. S5). Conductive silicon tubes were used as sampling lines for the SMPS and AMS to reduce electrostatic losses of particles, whilst all other instruments had FEP Teflon feed lines. Losses of VOCs and particles in the transfer lines are estimated to be less than $5 \%$ (Liu et al., 2015). 


\section{Results and discussion}

\subsection{Gas-phase analysis}

\subsubsection{Peak identification and yields}

Significant fragmentation was observed in the PTR-TOF upon injection of starting materials into a clean reactor. $\alpha$ Phellandrene was detected at $m / z, 137$ at 32-34\% depending on drift tube conditions, consistent with fragmentation observed in the PTR-MS studies of Misztal et al. (2012) and Tani (2013) (Supplement Sect. S2). Acetonitrile was found exclusively at $m / z, 42$ and remained constant throughout all experiments, indicating that dilution effects in the reactor are negligible. Despite having a lower proton affinity than water, cyclohexane was detected at $m / z 85$, although overall sensitivity is greatly reduced. The detection of cyclohexane is likely the result of termolecular reactions in the PTR-TOF (Smith and Španěl, 2005). Meanwhile, in a separate characterisation experiment, formic acid was found at $m / z$ 47, with minor fragments at $m / z 48,49$ and $65(<2 \%)$.

Observed interferences are expected to impact detection of $\alpha$-phellandrene's degradation products, biasing signals to lower $m / z$. Aldehyde, ketone, alcohol, ester and acid-bearing compounds are known to dehydrate following protonation to yield a $\mathrm{MH}^{+}\left(-\mathrm{H}_{2} \mathrm{O}\right)$ daughter ion (Smith and Španěl, 2005; Blake et al., 2006). Furthermore, multifunctional carbonyl compounds can eject a second water molecule from nascent $\mathrm{MH}^{+}$ions yielding a $\mathrm{MH}^{+}\left(-\mathrm{H}_{2} \mathrm{O}\right)_{2}$ daughter ion, whilst complex acid-bearing molecules have been observed to fragment via the loss of formic acid to produce $\mathrm{MH}^{+}(-\mathrm{HCOOH})$ ions and esters through ejection of $-\mathrm{OR}$ groups to yield $\mathrm{MH}^{+}(-\mathrm{ROH})$ (Španěl et al., 1997; Španěl and Smith, 1998). Uncertainty arising from fragmentation limits quantitative analysis for the majority of species, with standards neither available nor prepared. Nevertheless, Table 2 lists peaks routinely detected by the PTR-TOF across the 11 experiments. Note that $\mathrm{m} / \mathrm{z}$ includes the addition of $\mathrm{H}^{+}$.

Figure 2 shows time profiles of major species detected by the PTR-TOF during the ozonolysis of $\alpha$-phellandrene. For clarity, peaks have been corrected for background readings recorded prior to the introduction of ozone. Upon injection of ozone, $\alpha$-phellandrene is rapidly oxidised forming a number of product ions at low concentrations that continually increase throughout the experiment. Meanwhile, ozone, after rapid initial consumption, slowly decreases throughout the experiment in part due to losses to the reactor walls (Wang et al., 2014). The stability of acetonitrile and cyclohexane signals supports the finding of Wang et al. (2014) that wall losses are relatively minor for volatile organics in the GIGCAS chamber.

Ignoring conformational isomerism, the ozonolysis of $\alpha$ phellandrene can yield four unique CIs (Fig. 1) (MackenzieRae et al., 2016), with the degradation mechanism of CI3

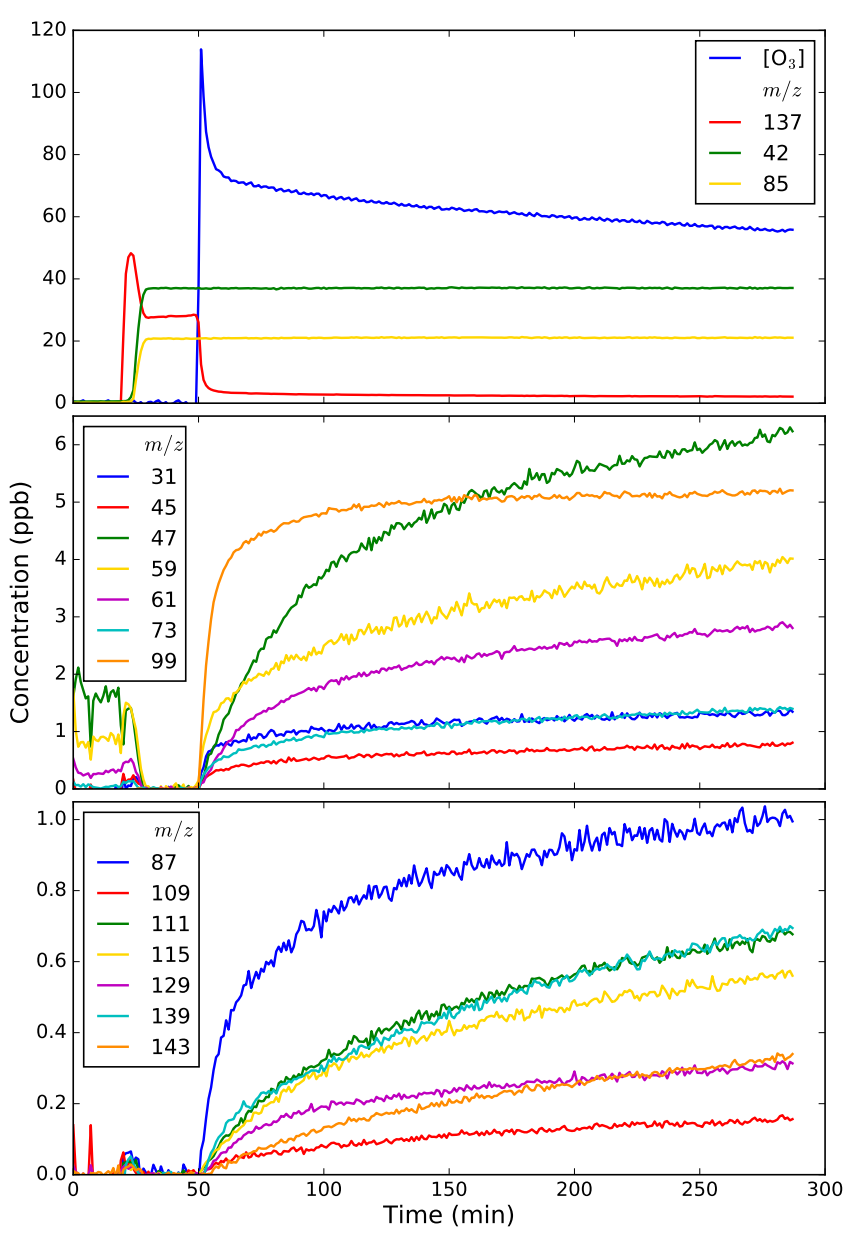

Figure 2. Time profiles of major species detected using the PTRTOF during the ozonolysis of $\alpha$-phellandrene in experiment 5 . The peak of $\alpha$-phellandrene observed upon its addition was the result of the reactor fans being switched on immediately prior to the introduction of acetonitrile in this experiment.

provided in Fig. 3. Detailed schematics of the remaining CIs are provided in the Supplement (Sect. S1) and lead to products isomeric to those shown in Fig. 3. A focus is on $\mathrm{RO}_{2}-$ $\mathrm{RO}_{2}$ radical chemistry which, due to the large rate constant of $\alpha$-phellandrene with ozone and lack of competing radical termination channels, dominates under the considered reaction conditions.

Elucidating the mechanism of $\alpha$-phellandrene, one expects initially to form a large range of first-generation products; however, none of the product ions detected were observed to decrease over the course of the chamber experiments, suggesting that detected ions in part correspond to secondgeneration species. For example, from the sCIs, one might expect an unsaturated keto-aldehyde or dialdehyde product (Fig. 5), analogous to pinonaldehyde from $\alpha$-pinene and limonaldehyde from limonene, to be detected at $m / z$ 169. Indeed, this signal was observed, but it continued to increase in concentration after $\alpha$-phellandrene was consumed, suggest- 
Table 2. Identified ions detected by the PTR-TOF. Refer to Fig. 3 for product structures.

\begin{tabular}{|c|c|c|c|}
\hline & $m / z$ & Formula & Assignment \\
\hline $\begin{array}{l}\text { Primary } \\
\text { signals }\end{array}$ & $\begin{array}{l}21 \\
37 \\
55\end{array}$ & $\begin{array}{l}\mathrm{H}_{3} \mathrm{O}^{18+} \\
\left(\mathrm{H}_{2} \mathrm{O}\right)_{2} \mathrm{H}^{+} \\
\left(\mathrm{H}_{2} \mathrm{O}\right)_{3} \mathrm{H}^{+}\end{array}$ & $\begin{array}{l}\text { Hydronium ion } \\
\text { Water cluster } \\
\text { Water cluster }\end{array}$ \\
\hline Acetonitrile & 42 & $\mathrm{CH}_{3} \mathrm{CNH}^{+}$ & Acetonitrile \\
\hline Cyclohexane & $\begin{array}{r}28,39,40,41,42,43,44,54,55,56,57 \\
58,67,68,69,70,82,83,84,85,86 \\
81,99,100,116,117 \\
83,101\end{array}$ & $\begin{array}{l}\mathrm{C}_{6} \mathrm{H}_{12} \mathrm{H}^{+} \\
\mathrm{C}_{6} \mathrm{H}_{10} \mathrm{OH}^{+} \\
\mathrm{C}_{6} \mathrm{H}_{12} \mathrm{OH}^{+}\end{array}$ & $\begin{array}{l}\text { Cyclohexane and fragments } \\
\text { Cyclohexanone } \\
\text { Cyclohexanol }^{\mathrm{a}}\end{array}$ \\
\hline Formic acid & $47,48,49,65$ & $\mathrm{CH}_{2} \mathrm{O}_{2} \mathrm{H}^{+}$ & Formic acid \\
\hline Acetic acid & $43,61,62,79$ & $\mathrm{C}_{2} \mathrm{H}_{4} \mathrm{O}_{2} \mathrm{H}^{+}$ & Acetic acid \\
\hline$\alpha$-phellandrene & $\begin{array}{r}43,67,69,79,81,82,83,91,92 \\
93,94,95,109,119,121,135 \\
136,137,138,139,153\end{array}$ & $\mathrm{C}_{10} \mathrm{H}_{16} \mathrm{H}^{+}$ & See the Supplement (Sect. S2) \\
\hline $\begin{array}{l}\text { Ozonolysis } \\
\text { products }\end{array}$ & $\begin{array}{r}31 \\
45 \\
47 \\
59 \\
61 \\
73 \\
87 \\
115,97 \\
129,111 \\
143 \\
85^{\mathrm{c}}, 99,109,125,139,155 \\
167,169,185\end{array}$ & $\begin{array}{l}\mathrm{CH}_{2} \mathrm{OH}^{+} \\
\mathrm{C}_{2} \mathrm{H}_{4} \mathrm{OH}^{+} \\
\mathrm{CH}_{2} \mathrm{O}_{2} \mathrm{H}^{+} \\
\mathrm{C}_{2} \mathrm{H}_{2} \mathrm{O}_{2} \mathrm{H}^{+} \\
\mathrm{C}_{2} \mathrm{H}_{4} \mathrm{O}_{2} \mathrm{H}^{+} \\
\mathrm{C}_{3} \mathrm{H}_{4} \mathrm{O}_{2} \mathrm{H}^{+} \\
\mathrm{C}_{3} \mathrm{H}_{2} \mathrm{O}_{3} \mathrm{H}^{+} \\
\mathrm{C}_{6} \mathrm{H}_{10} \mathrm{O}_{2} \mathrm{H}^{+} \\
\mathrm{C}_{7} \mathrm{H}_{12} \mathrm{O}_{2} \mathrm{H}^{+} \\
\mathrm{C}_{7} \mathrm{H}_{10} \mathrm{O}_{3} \mathrm{H}^{+} \\
- \\
-\end{array}$ & $\begin{array}{l}\text { Formaldehyde } \\
\text { Acetaldehyde } \\
\text { Formic acid } \\
\text { Glyoxal } \\
\text { Acetic acid } \\
\text { Methyl glyoxal } \\
\text { Identified oxidation products }\end{array}$ \\
\hline
\end{tabular}

ing that the observed $m / z 169$ is not simply a direct product ion of $\alpha$-phellandrene. Other major first-generation product ions expected include $m / z 185$, which corresponds to a range of isomeric species formed through either excited or thermalised CI rearrangement reactions, whereby three oxygen atoms are added for no loss of carbon or hydrogen (e.g. acids, esters, epoxides, secondary ozonides), and $m / z$ 155, which can be formed through radical transfer and subsequent $\mathrm{CHO}$ loss in the hydroperoxide channel (Mackenzie-Rae et al., 2016). Both these ions were detected in the PTR-TOF but again had concentrations which increased throughout the experiments, suggesting that they have large contributions from saturated species. This continual increase remained true in experiments which added a large secondary dose of ozone after commencement of the reaction (Fig. S4.1), confirming the discussed ions as saturated.

A similar phenomenon, whereby a distinct lack of firstgeneration products was observed by a PTR-MS, occurred when studying the ozonolysis of $\alpha$-terpinene (Lee et al., 2006; Ng et al., 2006), a structurally similar endocyclic- conjugated monoterpene. In the studies of Lee et al. (2006) and $\mathrm{Ng}$ et al. (2006), first-generation products were observed using identical methods for other monoterpene species including 3 -carene, $\alpha$-pinene, $\beta$-pinene, terpinolene and myrcene. It is possible then that for highly reactive monoterpenes such as $\alpha$-terpinene and $\alpha$-phellandrene, concentrations of first-generation products do not accumulate sufficiently during experiments for gas-phase detection. However, as discussed Sect. 3.1.3 and 3.2.1, a simple rate-study analysis shows that residence lifetimes based on gas-phase reactions are sufficient, whilst analysis of saturation concentrations suggests that the majority of predicted first-generation products likely reside in the gas phase.

Recent literature has shown that functionalised organic species experience considerable losses to Teflon chamber walls through gas-wall partitioning (e.g. Matsunaga and Ziemann, 2010; Zhang et al., 2014; Yeh and Ziemann, 2015; Krechmer et al., 2016; La et al., 2016). Observations indicate that organic compounds are not lost to the reactor walls, but rather partition between the gas-phase and Teflon 


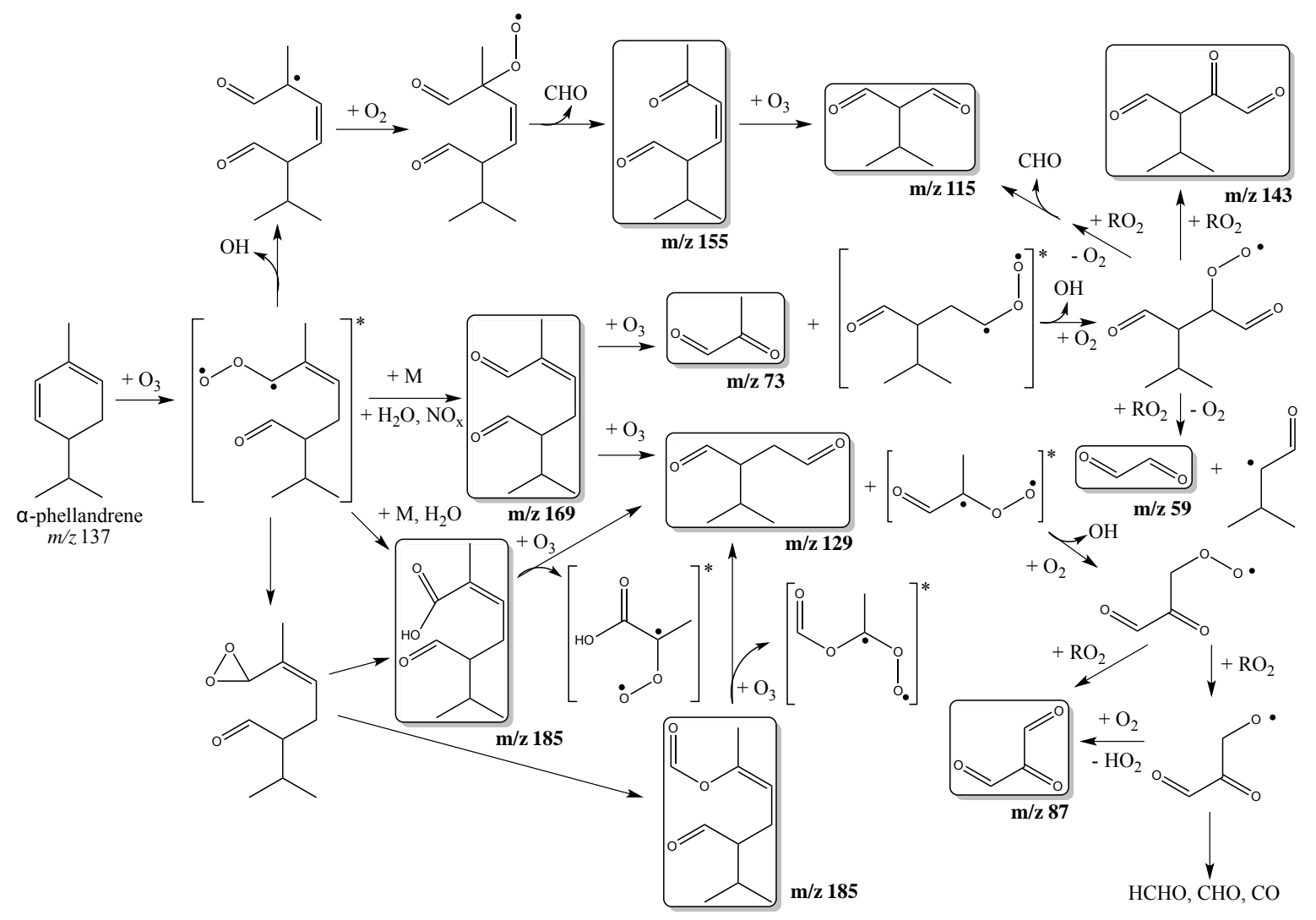

Figure 3. Partial mechanism for the ozonolysis of $\alpha$-phellandrene starting from CI3, yielding product masses detected by the PTR-TOF. Similar constructs for the remaining CIs are provided in the Supplement (Sect. S1).

walls in a reversible process that eventually reaches equilibrium, the speed of which is dependent on reactor geometry, turbulence and species diffusivity, and penetration and accommodation in the reactor walls. Based on the work of Krechmer et al. (2016), the timescale for reaching gaswall equilibrium in these experiments is thought to be less than $600 \mathrm{~s}$. Gas-wall partitioning therefore operates quick enough to affect the considered chamber experiments and detection of first-generation products. The relative impact of gaseous wall losses is further explored in Sect. 3.2.1; nonetheless, partitioning is strongly dependent on volatility, with losses of highly functionalised first-generation products of $\alpha$-phellandrene to reactor walls and/or sample lines during transfer into and detection by the PTR-TOF expected (Yeh and Ziemann, 2015; Krechmer et al., 2016; La et al., 2016).

Figure 2 shows that the highest product signal concentrations were observed for low $m / z$ species $\left(\leqslant \mathrm{C}_{3}\right)$. Whether this is an accurate representation of the system or a systematic bias from fragmentation is unknown; however, anecdotally increased counts of low mass species were observed as the energy of the drift tube was raised, suggesting that the latter does have some effect. Major peaks were found at $m / z 31$, $45,47,59,61$ and 73, corresponding to formaldehyde, acetaldehyde, formic acid, glyoxal, acetic acid and methyl gly- oxal, respectively. Although acetone also resides at $m / z$ 59, based on the low gas-chromatographic yields reported in Reissell et al. (1999) the signal is apportioned to glyoxal. As $\alpha$-phellandrene contains two double bonds, yields in this work were calculated as the slope of the least square regression between the change in concentration of the oxidation product and change in wall-loss-corrected ozone, as shown in Fig. 4, with ozone wall loss rates frequently characterised following the method described in Wang et al. (2014). The average yield from sequential ozonolysis is therefore calculated with results provided in Table 3. In practice, however, calculations are dominated by data points measured after the consumption of $\alpha$-phellandrene, with the data corresponding to the initial reaction of $\alpha$-phellandrene comparably limited and often largely excluded to reduce errors associated with having a finite reactor mixing time. As discussed later, this problem is navigated for $\mathrm{OH}$ radicals by using a higher PTR-TOF time resolution and measuring yields against $\alpha$ phellandrene consumption; however, mixing ratios of other oxidation products are too low in the initial stages of the experiment to produce reliable yield data in this regime. For experiments that had two additions of ozone (7 and 10), separate yield lines were fitted for data after each addition of ozone with the results then averaged, therefore maintaining 


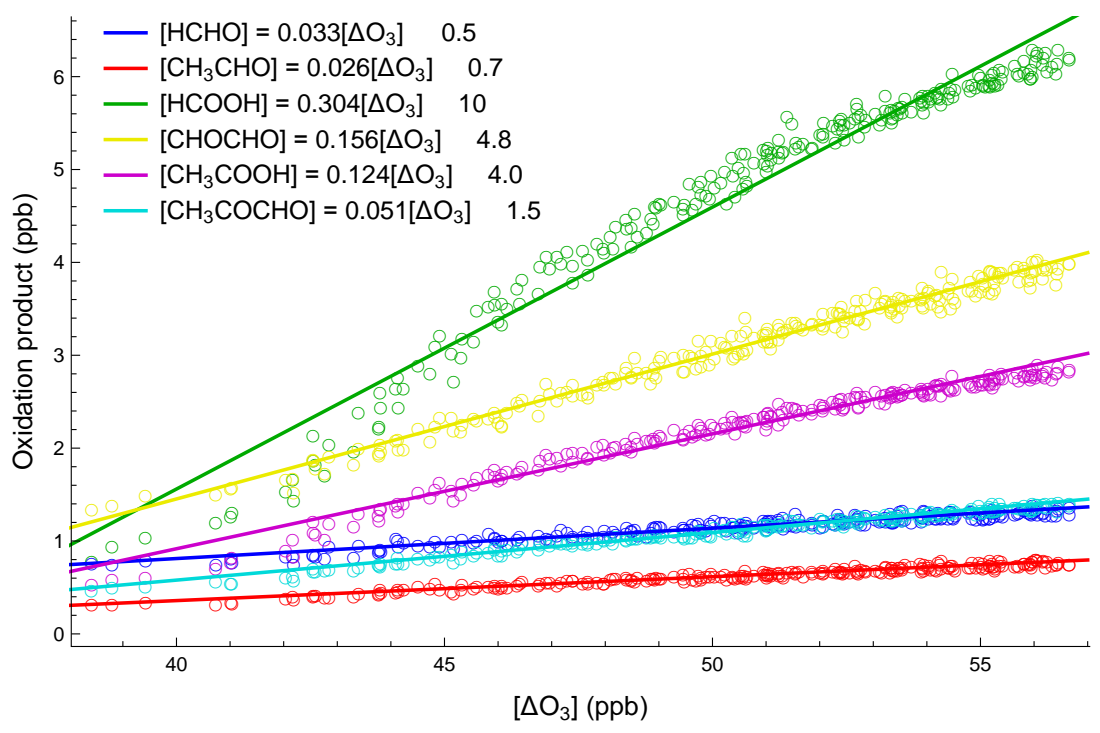

Figure 4. Determination of gas-phase product yields in experiment 5 .

Table 3. Gas-phase molar yields (\%) for major $\alpha$-phellandrene ozonolysis products.

\begin{tabular}{lrrrrrr}
\hline No. & Formaldehyde & Acetaldehyde & Formic acid & Glyoxal & Acetic acid & Methyl glyoxal \\
\hline 1 & $6.9 \pm 2$ & $8.3 \pm 2$ & $37 \pm 9.0$ & $23 \pm 5$ & $13 \pm 3$ & $3.7 \pm 0.9$ \\
2 & $5.9 \pm 1$ & $4.4 \pm 1$ & $24 \pm 6$ & $9.0 \pm 2$ & $9.0 \pm 2$ & $3.1 \pm 0.7$ \\
3 & $5.9 \pm 1$ & $5.4 \pm 1$ & $22 \pm 5$ & $6.2 \pm 1$ & $12 \pm 3$ & $2.0 \pm 0.5$ \\
4 & $5.0 \pm 1$ & $3.8 \pm 0.9$ & $28 \pm 6$ & $7.6 \pm 2$ & $11 \pm 2$ & $5.7 \pm 1$ \\
5 & $3.3 \pm 0.8$ & $2.6 \pm 0.6$ & $30 \pm 7$ & $16 \pm 4$ & $12 \pm 3$ & $5.1 \pm 1$ \\
6 & $7.0 \pm 2$ & $7.6 \pm 2$ & & $24 \pm 6$ & $22 \pm 5$ & $8.5 \pm 2$ \\
7 & $8.7 \pm 2$ & $0.2 \pm 0.04$ & & & $22 \pm 5$ & $3.4 \pm 0.8$ \\
8 & $5.4 \pm 1$ & $2.3 \pm 0.5$ & $28 \pm 6$ & $17 \pm 4$ & $16 \pm 4$ & $5.2 \pm 1$ \\
9 & $7.5 \pm 2$ & $2.5 \pm 0.6$ & $35 \pm 8$ & $21 \pm 5$ & $20 \pm 5$ & $5.3 \pm 1$ \\
10 & $7.9 \pm 2$ & $2.2 \pm 0.5$ & $29 \pm 7$ & $17 \pm 4$ & $13 \pm 3$ & $9.2 \pm 2$ \\
11 & $1.2 \pm 0.3$ & $0.41 \pm 0.09$ & $10 \pm 2$ & $7.6 \pm 2$ & $5.0 \pm 1$ & $2.1 \pm 0.5$ \\
\hline
\end{tabular}

the reported yield as an average of the entire ozonolysis system.

Formic and acetic acid were both found to be produced with high yields. The fragmentation pattern of acetic acid was determined in a separate calibration experiment, with $88 \%$ residing at $m / z 61$ and the remaining mass distributed over $m / z 43,62$ and 79 , corresponding to dehydration to the acylium ion, the ${ }^{13} \mathrm{C}$ isotope and protonation by a water cluster, respectively. Correcting for fragmentation, yields of formic and acetic acid were found to range from 22 to $37 \%$ and 9 to $22 \%$, respectively, across the conducted experiments. Yields of formic acid are considerably higher than what has been reported for the ozonolysis of other terpenes, whilst acetic acid yields are consistent with species containing an endocyclic bond (Lee et al., 2006); although a subtle difference in methodology should be noted with Lee et al. (2006) calculating yields with respect to the parent hydrocarbon. The addition of $\mathrm{NO}_{2}$ was found to reduce yields of both formic and acetic acid to $10 \pm 2$ and $5 \pm 1 \%$, respectively, with $\mathrm{O}_{3}$ losses through reaction with $\mathrm{NO}_{x}$ accounted for. The addition of $\mathrm{NO}_{2}$ therefore acts as an inhibitor to acidic group formation, likely by scavenging acyl peroxy radicals to form peroxyacyl nitrates (PANs). Alternatively, $\mathrm{NO}_{2}$ can impact the chemistry of the system by reacting with stabilised secondary ozonides (SOZs), although no changes in acid product yields were observed in the experiments where sCIs were scavenged, indicating that this channel is negligibly important in forming low-molecular-weight acids.

In characterising the PTR-TOF transmission curve, acetaldehyde and all other oxygenated VOCs in the gasstandard (Ionicon, Analytik GmbH, Austria) showed no evidence of fragmentation. Therefore, assuming no fragmentation for the remaining oxidation products provides yields of formaldehyde, acetaldehyde, glyoxal and methyl glyoxal of 5-9, 0.2-8, 6-23 and 2-9\%. Nevertheless, fragmentation of methyl glyoxal through CO loss in the PTR-TOF has been reported (Müller et al., 2012), which would simultaneously reduce its own yield whilst increasing the 
Table 4. Minor gas-phase molar yields (\%) for $\alpha$-phellandrene ozonolysis.

\begin{tabular}{lrrrrrrrr}
\hline No. & $m / z 87$ & $m / z 97$ & $m / z 109$ & $m / z 111$ & $m / z 115$ & $m / z 129$ & $m / z 139$ & $m / z 143$ \\
\hline 1 & $2.5 \pm 0.6$ & $1.1 \pm 0.3$ & $0.58 \pm 0.1$ & $2.9 \pm 0.7$ & $3.3 \pm 0.8$ & & $3.4 \pm 0.8$ & \\
2 & $2.5 \pm 0.6$ & $0.87 \pm 0.2$ & $0.19 \pm 0.04$ & & & & \\
3 & $3.2 \pm 0.8$ & $1.3 \pm 0.3$ & $0.61 \pm 0.1$ & $3.6 \pm 0.9$ & $3.0 \pm 0.7$ & & & \\
4 & $2.5 \pm 0.6$ & $0.21 \pm 0.05$ & $0.74 \pm 0.2$ & $3.6 \pm 0.9$ & $3.0 \pm 0.7$ & $1.3 \pm 0.3$ & $4.4 \pm 1$ & $1.9 \pm 0.5$ \\
5 & $3.5 \pm 0.8$ & $1.1 \pm 0.3$ & $0.78 \pm 0.2$ & $3.7 \pm 0.9$ & $3.0 \pm 0.7$ & $1.4 \pm 0.3$ & $3.7 \pm 0.9$ & $2.0 \pm 0.5$ \\
6 & $0.13 \pm 0.03$ & & $0.45 \pm 0.1$ & & & & & \\
7 & $0.75 \pm 0.2$ & & & & $2.4 \pm 0.6$ & & $4.7 \pm 0.4$ & $1.5 \pm 0.4$ \\
8 & $5.4 \pm 1$ & $2.0 \pm 0.5$ & $1.1 \pm 0.3$ & $4.8 \pm 1$ & $3.1 \pm 0.7$ & $1.4 \pm 0.3$ & $4.2 \pm 1$ & $4.4 \pm 1$ \\
9 & $2.3 \pm 0.5$ & $0.76 \pm 0.2$ & $0.68 \pm 0.2$ & $2.2 \pm 0.5$ & $3.0 \pm 0.7$ & $1.9 \pm 0.5$ & $3.8 \pm 0.9$ & $5.1 \pm 1$ \\
10 & $7.4 \pm 2$ & $2.7 \pm 0.6$ & $0.69 \pm 0.2$ & $4.0 \pm 0.9$ & $2.7 \pm 0.6$ & $6.0 \pm 1$ & $3.9 \pm 0.9$ & $4.4 \pm 1$ \\
11 & $0.12 \pm 0.03$ & $0.13 \pm 0.03$ & $0.15 \pm 0.03$ & $0.09 \pm 0.02$ & $0.91 \pm 0.2$ & $0.29 \pm 0.07$ & $0.40 \pm 0.09$ & $1.7 \pm 0.4$ \\
\hline
\end{tabular}

yield of acetaldehyde. A similar phenomenon is also expected of glyoxal; nonetheless, acetaldehyde yields remain low and consistent with findings reported for other terpene species. Formaldehyde yields are consistent with other terpene species containing multiple internal double bonds, e.g. $\alpha$-humulene and $\alpha$-terpinene (Lee et al., 2006). The addition of a sCI scavenger was found to have little impact on product distribution or yields, suggesting that the sCI-formic acid complexes ultimately decompose to produce similar gas-phase products to sCIs that degrade through conventional channels. Whether decoupling of the sCI-acid complex occurs inside the reactor or upon protonation in the PTR-TOF remains unknown. Similarly, no significant differences in yields were observed between experiment 9 and $\mathrm{OH}$-scavenged experiments, with decomposition into smaller carbon species counterintuitively invariant to action by the $\mathrm{OH}$ radical, strengthening the argument that fragmentation inside the PTR-TOF is non-negligible. Meanwhile, in experiment 11, yields of formaldehyde, acetaldehyde, glyoxal and methyl glyoxal were $1.2 \pm 0.3,0.41 \pm 0.09,7.6 \pm 2$ and $2.1 \pm 0.5 \%$, respectively. A comparison of rate constants of $\mathrm{O}_{3}$ with $\alpha$-phellandrene $\left(3.0 \times 10^{-15} \mathrm{~cm}^{3}\right.$ molecule $\left.\mathrm{s}^{-1} \mathrm{~s}^{-1}\right)$ and $\mathrm{NO}_{2}\left(3.5 \times 10^{-17} \mathrm{~cm}^{3}\right.$ molecule $\left.\mathrm{e}^{-1} \mathrm{~s}^{-1}\right)$ suggests that the majority of $\mathrm{O}_{3}$ will be consumed by $\alpha$-phellandrene with formation of the nitrate radical relatively minor (Calvert et al., 2000; Atkinson et al., 2004). Nevertheless, $\mathrm{NO}_{2}$ is in excess in the system, with a systematic reduction in product yields indicative of a shift towards $\mathrm{RO}_{2}$ - and $\mathrm{NO}_{2}$-dominated chemistry, producing peroxy-nitrate-containing products (Draper et al., 2015).

Heavier second-generation products routinely detected across experiments are listed in Table 2, with yields for a number of these products given in Table 4 . The absence of a yield indicates that the peak was not detected by the PTR-TOF, which typically occurred for minor peaks in experiments with lower starting $\alpha$-phellandrene concentrations. Again, no fragmentation was assumed in determining yields, although some ions do differ by common fragment mass amounts, suggesting that fragmentation may be important.
For example, $m / z 185$ and $167, m / z 129$ and 111 and $\mathrm{m} / \mathrm{z} 115$ and 97 all differ by $18 \mathrm{amu}$, suggesting that the latter masses could be dehydrated fragments. Whilst strong correlation $\left(R^{2}>0.99\right)$ between these pairs of peaks is observed, it is not consistent across the entire dataset, suggesting that there exist multiple contributors to the aforementioned signals. Similar instances are also observed for peaks separated by $28 \mathrm{amu}$ (e.g. $m / z 143$ and 115 ) and $46 \mathrm{amu}$ (e.g. $m / z 185$ and 139).

Calculated yields for these larger products were in general $<5 \%$, with detected products sufficiently volatile such that gas-wall partitioning losses are thought to be minor (see Fig. 9). Again, the presence of $\mathrm{OH}$ radicals in experiment 9 had little effect on product yields. Addition of $\mathrm{NO}_{2}$ to the system in experiment 11 resulted in significantly reduced yields, with overall distribution remaining similar and no new peaks or evidence of nitrate-containing compounds observed. Nonetheless, alkyl nitrates are known to readily lose $\mathrm{HNO}_{3}$ after protonation in the PTR-TOF, resulting in the formation of bare alkyl ions (D'Anna et al., 2005; Aoki et al., 2007; Duncianu et al., 2017). Proposed structures for some of these larger second-generation products, along with plausible formation mechanisms, are shown in Fig. 3, although it is possible that more than one species contributes to an observed oxidation product mass. A large number of products also remain unidentified, with their $m / z$ unable to be transcribed to plausible, mechanistically derived structures.

Figure 2 shows that product signals at $m / z 31,59,73$ and 87 show a sharp increase upon commencement of the reaction, suggesting that these products are formed directly from $\alpha$-phellandrene ozonolysis. Nevertheless, a large fraction of the product mass for these ions is generated after $\alpha$ phellandrene consumption, indicating that yields are largely driven by contributions from second-generation species. Slower initial production of the remaining ions suggests that their formation is linked to consumption of first-generation products. Interestingly, the peaks corresponding to the heaviest ions, $m / z, 167,169$ and 185 , have relatively constant temporal profiles which also lack an accelerated increase upon 


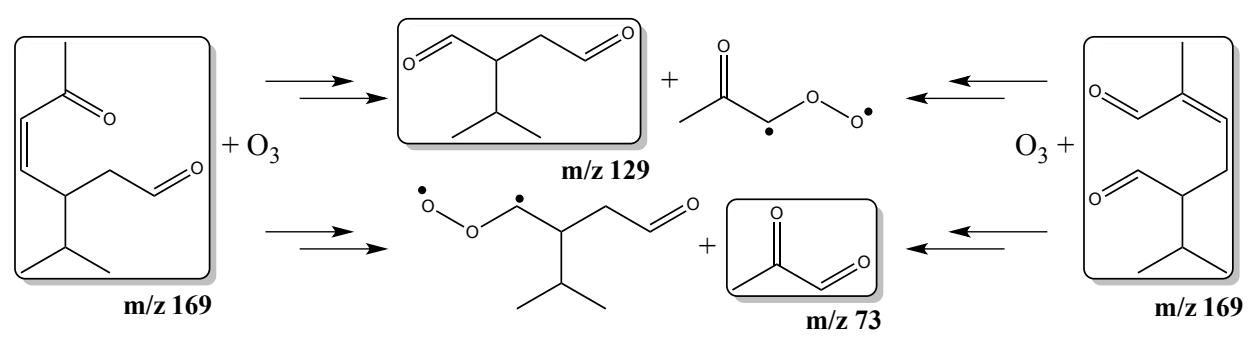

Figure 5. Mechanism of $\mathrm{O}_{3}$ addition to the proposed $\mathrm{m} / \mathrm{z} 169$ structures, yielding pairs of Criegee intermediates and carbonyl-containing products.

a second addition of ozone, a feature that is apparent among lighter product ions. Their unique time profiles imply that they are derived from a source secondary to ozonolysis, such as gas-phase accretion reactions, with modelling support for this provided in the Supplement (Sect. S4).

Formation of prescribed products after the second ozonolysis is in agreement with the proposed degradation mechanism (Fig. 3), which predicts a number of both small and large species to form upon fragmentation of the carbon backbone. A large fraction of the smaller products come from decomposition of the three-carbon system $\left(\mathrm{C}_{1}-\mathrm{C}_{2}-\mathrm{C}_{7}\right.$; Fig. 1) bridging the conjugated double bonds in $\alpha$-phellandrene, which segment from the rest of the molecule after the second ozone addition. For example, plausible mechanisms can be traced to methyl glyoxal formation irrespective of the order of addition of ozone to the two double bonds, with the only prerequisite being that the first addition of ozone adds one carbonyl group to the $\mathrm{C}_{1}-\mathrm{C}_{2}-\mathrm{C}_{7}$ system. An example showing this from a proposed first-generation product is provided in Fig. 5. Subsequent decomposition of the $\mathrm{C}_{1}-\mathrm{C}_{2}-$ $\mathrm{C}_{7}$ Criegee biradical fragment can yield products including formaldehyde, formic acid and acetic acid. Meanwhile, functionalisation of the larger seven-carbon system bridging the conjugated bonds in $\alpha$-phellandrene can give rise to a large number of heavier second-generation products. The $m / z 129$ is assigned to 2-propan-2-ylbutanedial, which can be formed from a number of pathways (e.g. Fig. 3). The $m / z 115$ is assigned to 2-propan-2-ylpropanedial, which is formed if a CI from either addition participates in the hydroperoxide channel, resulting in CHO fragmentation. Conversely, if instead of fragmentation, stabilisation occurs after a 1,5-hydrogen shift, then the product detected at $m / z 143$ shown in Fig. 3 may form. In all instances, detected second-generation products can be formed from a wide variety of predicted firstgeneration products independent of the order of addition of ozone to the two double bonds (Supplement Sect. S1).

\subsubsection{Determination of $\mathrm{OH}$ yields}

The $\mathrm{OH}$ radical scavenger, cyclohexane, reacts with $\mathrm{OH}$ to form both cyclohexanone and cyclohexanol (Atkinson et al., 1992; Berndt et al., 2003), with cyclohexanone $(\mathrm{m} / z$ 99) used as the $\mathrm{OH}$ radical tracer in this study. In a character- isation experiment, 98 and $85 \%$ of cyclohexanone (Sigma Aldrich, 99.8\%) was found to reside at $\mathrm{m} / z$. 99 when the PTR-TOF drift tube was operated at 112 and $136 \mathrm{Td}$, respectively, with the remaining mass distributed over dehydrated and cluster peaks at $m / z 81,116$ and 117 . A minor ozonolysis product is also detected at $m / z 99$ (Sect. 3.1.1); however, the two peaks are resolvable in the PTR-TOF.

A major uncertainty in determining $\mathrm{OH}$ yields is the yield of cyclohexanone formed from the reaction of cyclohexane with OH radicals. Atkinson et al. (1992) reported the combined yield of cyclohexanone and cyclohexanol to be $0.55 \pm 0.09$, with cyclohexanone/cyclohexanol ratios typically ranging from 0.8 to 1.4 , depending on the terpene investigated. In contrast, Berndt et al. (2003) reported a cyclohexanone yield of $0.53 \pm 0.06$. In this study, the $\mathrm{OH}$ yield is based on the average of these two findings, with a cyclohexanone yield from the reaction of $\mathrm{OH}$ and cyclohexane of $0.41 \pm 0.14$ used. Scavenging is assumed to be $95 \%$ efficient based on the volume of cyclohexane introduced into the reactor, with the error in this assumption thought to be minimal with respect to the inherent uncertainty in cyclohexanone yields. Background interference from cyclohexane, of which a small portion is oxidised by $\mathrm{O}_{2}^{+}$to cyclohexanone in the drift tube, is corrected for (Winterhalter et al., 2009).

$\mathrm{OH}$ yields for the initial reaction of ozone with $\alpha$ phellandrene were calculated from the slope of $\mathrm{OH}$ produced against $\alpha$-phellandrene reacted. As both $m / z 99$ and 137 are major signals in the PTR-TOF, spectra were not averaged during analysis, resulting in a $2 \mathrm{~s}$ time resolution. A characteristic OH-production time profile is shown in Fig. 6, which can be separated into three regions. The initial part of the experiment is characterised by a linear section, where $\alpha$-phellandrene is the primary source of $\mathrm{OH}$ radicals. The gradient obtained from linear regression in this regime is equivalent to the $\mathrm{OH}$ yield from ozonolysis of the first double bond in $\alpha$-phellandrene (Fig. 7a). The $\alpha$ phellandrene-dominated regime is short-lived with respect to total $\mathrm{OH}$ production time in the reactor, suggesting that first-generation products are also highly reactive and large producers of $\mathrm{OH}$ radicals. As the reaction proceeds, fasterreacting first-generation products begin to contribute to the $\mathrm{OH}$ budget, whilst $\alpha$-phellandrene becomes increasingly less 
Table 5. Measured and modelled $\mathrm{OH}$ radical yields and modelled rate constants for $\alpha$-phellandrene ozonolysis experiments.

\begin{tabular}{|c|c|c|c|c|c|c|}
\hline & \multicolumn{3}{|c|}{$\alpha$-phellandrene } & \multicolumn{3}{|c|}{ First-generation products } \\
\hline & $\begin{array}{r}k_{1}\left(10^{-15} \mathrm{~cm}^{3}\right. \\
\left.\text { molecule }{ }^{-1} \mathrm{~s}^{-1}\right)\end{array}$ & $\begin{array}{l}\text { Experimental } \\
\text { OH yield }(\%)\end{array}$ & $\begin{array}{r}\text { Modelled OH } \\
\text { yield (\%) }\end{array}$ & $\begin{array}{r}k_{2}\left(10^{-16} \mathrm{~cm}^{3}\right. \\
\left.\text { molecule }{ }^{-1} \mathrm{~s}^{-1}\right)\end{array}$ & $\begin{array}{l}\text { Experimental } \\
\text { OH yield }(\%)\end{array}$ & $\begin{array}{r}\text { Modelled } \mathrm{OH} \\
\text { yield }(\%)\end{array}$ \\
\hline 1 & 2.0 & $29 \pm 8$ & 48 & 0.7 & $10 \pm 2$ & 10 \\
\hline 2 & 2.0 & $25 \pm 8$ & 55 & 2.0 & $27 \pm 5$ & 13 \\
\hline 3 & 2.0 & $25 \pm 8$ & 48 & 1.5 & $16 \pm 4$ & 11 \\
\hline 4 & 2.0 & $21 \pm 7$ & 46 & 0.6 & $10 \pm 2$ & 8 \\
\hline 5 & 2.0 & $28 \pm 8$ & 45 & 1.0 & $11 \pm 3$ & 10 \\
\hline 6 & 3.0 & $54 \pm 14$ & 57 & 0.3 & $20 \pm 4$ & 20 \\
\hline 7 & 3.0 & $48 \pm 13$ & 65 & 1.0 & $10 \pm 3$ & 23 \\
\hline 8 & 2.0 & $43 \pm 14$ & 68 & 2.0 & - & 10 \\
\hline 10 & 2.0 & $47 \pm 11$ & 46 & 0.3 & - & 15 \\
\hline Lit. & $3.0 \pm 1^{\mathrm{a}}$ & $26-31^{b}$ & & & $8-11^{b}$ & \\
\hline
\end{tabular}

a Calvert et al. (2000).

${ }^{\mathrm{b}}$ Herrmann et al. (2010).

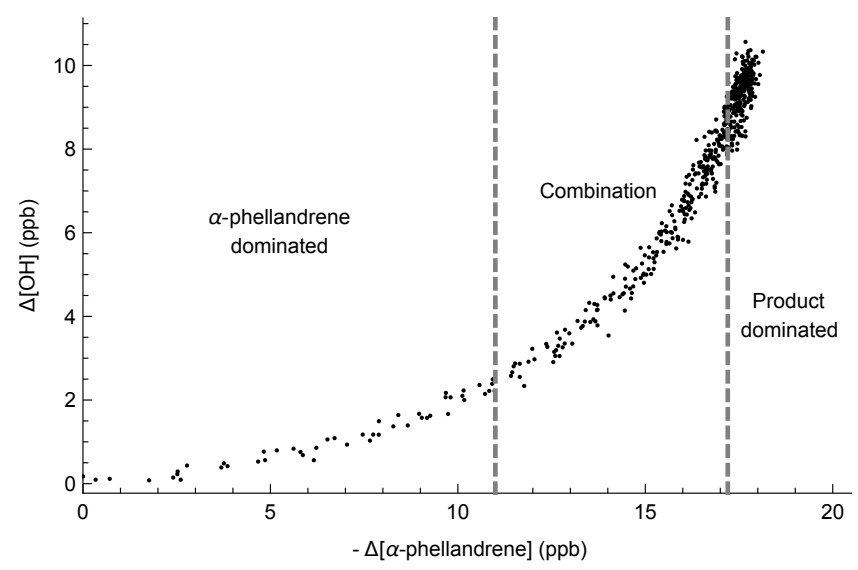

Figure 6. $\mathrm{OH}$ radical production versus $\alpha$-phellandrene consumption for the first $18 \mathrm{~min}$ of experiment 3 .

influential. This results in a gradual curve, until essentially all $\alpha$-phellandrene has been consumed and a vertical path is traced, indicating that first-generation species are now dominating $\mathrm{OH}$ radical production. By plotting $\mathrm{OH}$ formation against $\mathrm{O}_{3}$ consumption in the product-dominated regime, the collective first-generation product $\mathrm{OH}$ radical yield is obtained (Fig. 7b). Naturally, this method is only applicable to those experiments where the product-dominated regime is attained, which is why no $\mathrm{OH}$ radical yields are reported for first-generation products in experiments 8 and 10 . OH yields from the reaction of $\alpha$-phellandrene and its first-generation degradation products with ozone are listed in Table 5.

The average $\mathrm{OH}$ yield for the reaction of the first double bond in $\alpha$-phellandrene across the 10 experiments was found to be $35 \pm 12 \%$, whilst the average $\mathrm{OH}$ yield from the ozonolysis of the second reacting double bond was $15 \pm 7 \%$. Both these determined values are slightly higher than the values calculated in Herrmann et al. (2010), although they agree (a)

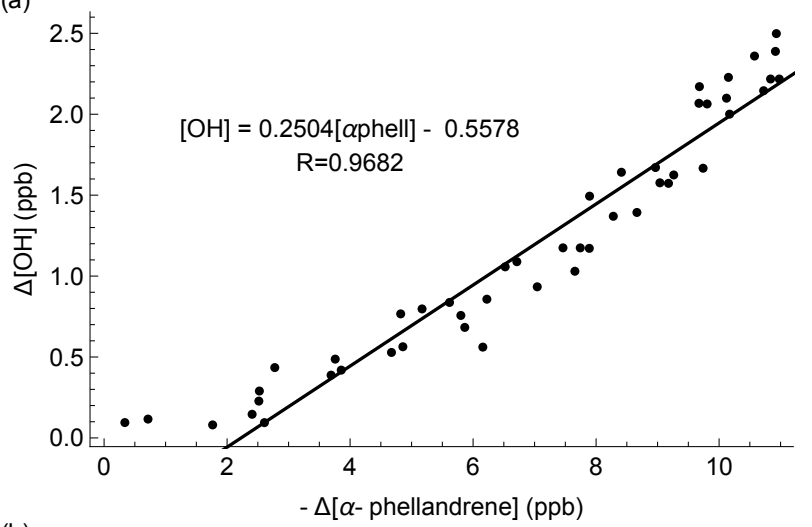

(b)

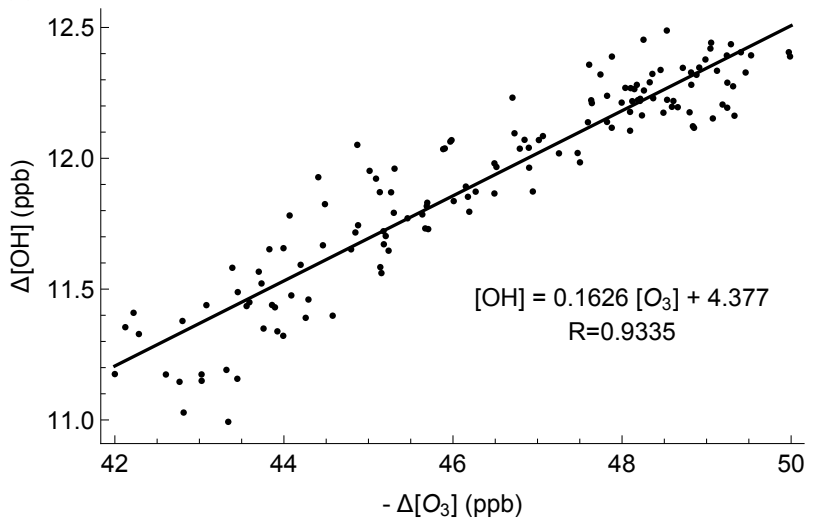

Figure 7. OH production from the (a) first and (b) second addition of ozone to $\alpha$-phellandrene in experiment 3 against $\alpha$-phellandrene and ozone consumption, respectively.

well within uncertainty limits. Whilst experimental methodology is similar, Herrmann et al. (2010) conducted their analysis under the assumption that the two double bonds in $\alpha$ phellandrene react at significantly different rates, such that 
$95 \%$ of $\alpha$-phellandrene reacts before first-generation products start to be consumed. However, as Fig. 6 shows, firstgeneration products contribute to the $\mathrm{OH}$ radical budget considerably earlier than this. As a result, Herrmann et al. (2010) is likely to have underpredicted $\mathrm{OH}$ yields of first-generation products, inadvertently apportioning their contribution to $\alpha$ phellandrene, whose $\mathrm{OH}$ yields would subsequently be overpredicted. The method employed in this study is thought to provide a more accurate distinction between $\mathrm{OH}$ radical production from $\alpha$-phellandrene and its first-generation products. From the determined yields, it can be concluded that the hydroperoxide channel does play an important role in the decomposition of $\alpha$-phellandrene by ozone, supportive of findings from a recent theoretical study (Mackenzie-Rae et al., 2016).

\subsubsection{Modelling rate constants and $\mathrm{OH}$ yields}

The conjugated system in $\alpha$-phellandrene provides two reactive sites for ozone addition. Based on analogy with rate constants from simpler alkenes, such as cyclohexene $\left(k=8.1 \times 10^{-17} \mathrm{~cm}^{3}\right.$ molecule $\left.{ }^{-1} \mathrm{~s}^{-1}\right)$ and 1-methyl-1cyclohexene $\left(k=1.66 \times 10^{-16} \mathrm{~cm}^{3}\right.$ molecule $\left.\mathrm{e}^{-1} \mathrm{~s}^{-1}\right)($ Calvert et al., 2000), inductive effects are expected to make the methyl-substituted double bond the more reactive addition site. However, recent theoretical results suggest the contrary (Mackenzie-Rae et al., 2016), with steric effects raising the energy barrier for entry to the more substituted double bond, resulting in addition to the less substituted double bond in $\alpha$ phellandrene being favoured. This finding is consistent with experimental evidence for isoprene, where methacrolein, not methyl vinyl ketone, is the favoured first-generation product (Paulson et al., 1992; Grosjean et al., 1993; Aschmann and Atkinson, 1994; Rickard et al., 1999). Nevertheless, the average energy difference for addition to the two double bonds is minor, with both entry channels expected to be important.

Given the high chemical reactivity of both double bonds in $\alpha$-phellandrene, it is interesting to investigate the reactivity of first-generation products. The following reaction parameterisation was therefore constructed to determine the average rate constant of ozone with all first-generation species:

$$
\begin{gathered}
\alpha-\text { phellandrene }+\mathrm{O}_{3} \stackrel{k_{1}}{\longrightarrow} \mathrm{FG}+x \mathrm{OH} \\
\mathrm{FG}+\mathrm{O}_{3} \stackrel{k_{2}}{\longrightarrow} \mathrm{SG}+y \mathrm{OH} \\
\mathrm{O}_{3} \stackrel{k_{3}}{\longrightarrow} \mathrm{wO}_{3},
\end{gathered}
$$

where FG represents all first-generation products, SG represents all second-generation products, $\mathrm{wO}_{3}$ is ozone lost to the reactor walls and $x$ and $y$ are stoichiometric coefficients representing $\mathrm{OH}$ yields from each reaction step. The rate constant for the reaction of ozone with $\alpha$-phellandrene $\left(k_{1}\right)$ was constrained to the literature value (Calvert et al., 2000 ), whilst a first-order ozone wall loss rate of $k_{3}=2$ $8 \times 10^{-6} \mathrm{~s}^{-1}$ was used based on a number of calibration ex- periments. Remaining parameters, namely $x, y$ and $k_{2}$, were varied to optimise model performance. The reaction scheme was solved using the online numerical integrator AtChem (https://atchem.leeds.ac.uk/) for all experiments, barring 9 and 11 due to the unconstrained influence of $\mathrm{NO}_{2}$ and/or $\mathrm{OH}$ radicals.

Figure 8 shows the results of the simulation of ozone consumption and $\mathrm{OH}$ production for three different experiments, with optimised parameters for each experiment given in Table 5. Considering simplicity, the model performs surprisingly well. Based on all experiments, the average simulated rate constant for the reaction of first-generation products with ozone was $k_{2}=1.0 \pm 0.7 \times 10^{-16} \mathrm{~cm}^{3}$ molecule ${ }^{-1} \mathrm{~s}^{-1}$. Although the ozonolysis of first-generation products is around 30 times slower than that of $\alpha$-phellandrene, it is still faster than the ozonolysis of numerous monoterpenes including $\alpha$-pinene, $\beta$-pinene, sabinene, 3 -carene and $\beta$-phellandrene (Calvert et al., 2000). Using a typical background tropospheric ozone mixing ratio of $30 \mathrm{ppb}$, atmospheric lifetimes $(\tau)$ of $\alpha$-phellandrene and its first-generation products can be estimated by

$\tau_{i}=\frac{1}{k_{i}\left[\mathrm{O}_{3}\right]}$.

The atmospheric lifetime of $\alpha$-phellandrene is therefore $\tau_{1} \sim$ $7.5 \mathrm{~min}$, whilst the average lifetime of first-generation products is calculated to be $\tau_{2} \sim 3.75 \mathrm{~h}$. Both $\alpha$-phellandrene and its first-generation products therefore have a relatively short atmospheric lifetime with respect to ozone and are unlikely to be involved in long-range transport phenomena. Instead, complete saturation likely occurs in the chemical environment to which $\alpha$-phellandrene is emitted, thus impacting the local radical, acid and SOA budgets. Interestingly, increasing the ozone concentration to conditions found in chamber experiments results in first-generation product lifetimes of the order of tens of minutes, which is more than sufficient for gas-phase detection. The inability to detect first-generation products is therefore indicative of an underlying sampling or detection issue.

$\mathrm{OH}$ production is additionally included in the model to assist in parameterising yields from $\alpha$-phellandrene and the average of its first-generation products. Experimental assessment of $\mathrm{OH}$ yields carries an inherent uncertainty, in that linear regression was used to fit data belonging to a segment of a curve (Fig. 5), with information in the "combination" section notionally discarded. Model parameterisation allows for a more complete description, although mechanistic simplicity renders the results far from quantitative. Instead, its purpose is to both validate experimental findings and allow further constraints to be placed on $\mathrm{OH}$ production from the $\alpha$-phellandrene system.

The average modelled $\mathrm{OH}$ yields are $53 \pm 10$ and $13 \pm 5 \%$ for $\alpha$-phellandrene and its average first-generation products, respectively. The model suggests $\alpha$-phellandrene makes a greater contribution to the $\mathrm{OH}$ budget than what was cal- 


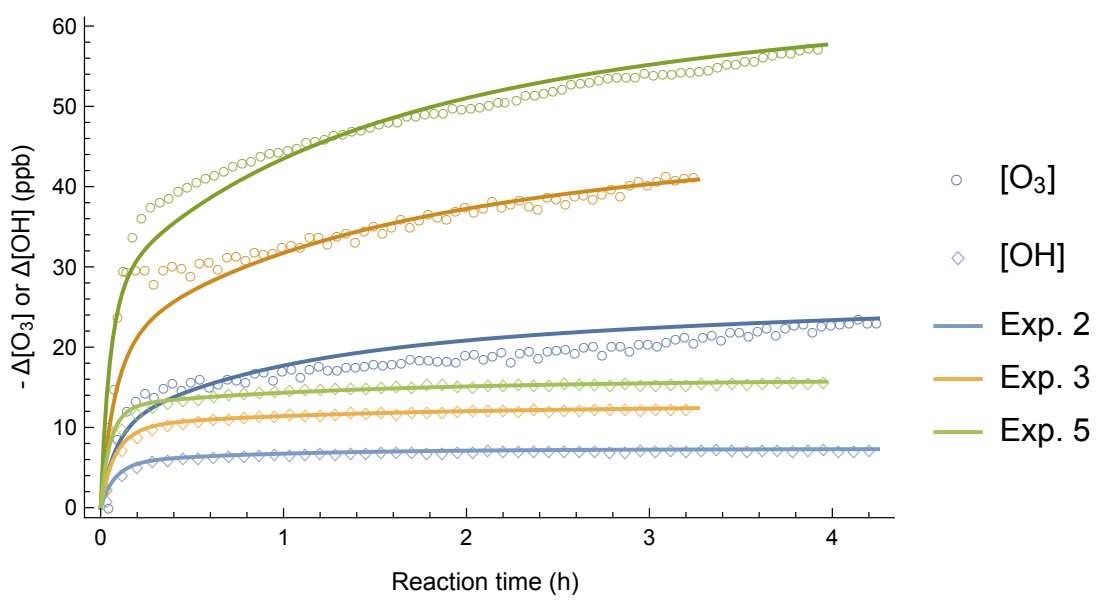

Figure 8. Plot of consumption of ozone and $\mathrm{OH}$ production against reaction time for experiments 2 (blue), 3 (yellow) and 5 (green). Experimental data are represented by open circles for $\mathrm{O}_{3}$ and open diamonds for $\mathrm{OH}$, whilst solid lines are modelled results using parameters listed in Table 5.

culated experimentally, whilst yields from first-generation products are consistent with experimental measurements. Overall, net $\mathrm{OH}$ radical production is greater from the model than experimental measurements. The source of this discrepancy is likely the limited data used in calculating $\alpha$ phellandrene's $\mathrm{OH}$ yields, with a large proportion of $\alpha$ phellandrene consumed in the combination section. Given that the $\alpha$-phellandrene-dominated regime generally lasted around 2-3 min, which is comparable to the mixing time of the reactor, it is entirely possible that $\mathrm{OH}$ production in this regime was not characterised well. The experimental finding for $\mathrm{OH}$ radical production from $\alpha$-phellandrene of $35 \pm 12 \%$ is therefore recommended as a lower bound.

\subsection{Particle-phase analysis}

\subsubsection{SOA formation}

First- and second-generation ozonolysis products are highly functionalised polar species with high molecular weights. It is therefore expected that they should make a significant contribution to the aerosol phase through gas-particle partitioning (Pankow, 1994; Odum et al., 1996). To assess this, the saturation vapour concentration $\left(C^{*}, \mu \mathrm{g} \mathrm{m}^{-3}\right)$ (Donahue et al., 2006, 2012) of each species was calculated. Vapour pressures were estimated using the Extended Aerosol Inorganic Model (E-AIM) (Clegg et al., 2008), using the structure-based estimator of Nannoolal et al. (2004) for boiling points coupled with Moller et al. (2008) for vapour pressures. This method has been compared extensively with other estimation techniques (Barley and McFiggans, 2010; O'Meara et al., 2014). Activity coefficients were calculated using the UNIversal Functional Activity Coefficient (UNIFAC) method (Fredenslund et al., 1975). The saturation vapour concentrations calculated are shown in twodimensional volatility oxidation space in Fig. 9.
Gas-particle partitioning occurs in competition with gaswall partitioning, a process that is also dependent on species saturation vapour concentrations (Supplement Sect. S6). In parameterising gas-wall partitioning, the Teflon film is often considered to have an equivalent organic aerosol mass concentration $\left(C_{\mathrm{w}}\right)$. Values for $C_{\mathrm{w}}$ vary significantly in the literature, with Ziemann and co-workers reporting values of $C_{\mathrm{w}} \sim 2-40 \mathrm{mg} \mathrm{m}^{-3}$ (Matsunaga and Ziemann, 2010; Yeh and Ziemann, 2015), Zhang et al. (2014) reporting $C_{\mathrm{w}}$ values from 0.0004 to $300 \mathrm{mg} \mathrm{m}^{-3}$ and Krechmer et al. (2016) showing values of $C_{\mathrm{w}}$ to vary with $C^{*}$, from $C_{\mathrm{w}}=0.016 \mathrm{mg} \mathrm{m}^{-3}$ for $C^{*}<1$ up to $30 \mathrm{mg} \mathrm{m}^{-3}$ for $C^{*}>$ $10^{4}$. The reasons for the large discrepancies between studies are unknown; however, they are likely due to differing deformation and activities of the Teflon walls (Krechmer et al., 2016). Nonetheless, comparing reported values to SOA loadings generated during the chamber experiments reported in this work, it is evident that gas-wall partitioning is at least competitive, if not dominant, compared to gas-particle partitioning. The impact is shown in Fig. 9 by plotting the fraction of an organic species that remains in the gas phase over different saturation vapour concentrations using $C_{\mathrm{w}}=$ $5 \mathrm{mg} \mathrm{m}^{-3}$ and an SOA loading of $200 \mu \mathrm{g} \mathrm{m}^{-3}$. Under this scenario, gas-wall partitioning dominates, with compounds having $C^{*}<10^{2} \mu \mathrm{g} \mathrm{m}^{-3}$ predominantly residing in the walls with a small fraction in the aerosol phase after equilibrium is established, whereas species with $C^{*}>10^{6} \mu \mathrm{g} \mathrm{m}^{-3}$ remain almost entirely in the gas phase. Compounds with $10^{2}<C^{*}<10^{6} \mathrm{\mu g} \mathrm{m}^{-3}$ will partition to varying extents depending on their volatility and functional group composition between the wall, gas and particle phases (Krechmer et al., 2016). However, no corrections for gas-particle partitioning are made in the present study, given that no product vapour loss rate measurements were made for the GIG-CAS chamber and the large variability in literature values of $C_{\mathrm{w}}$. With- 


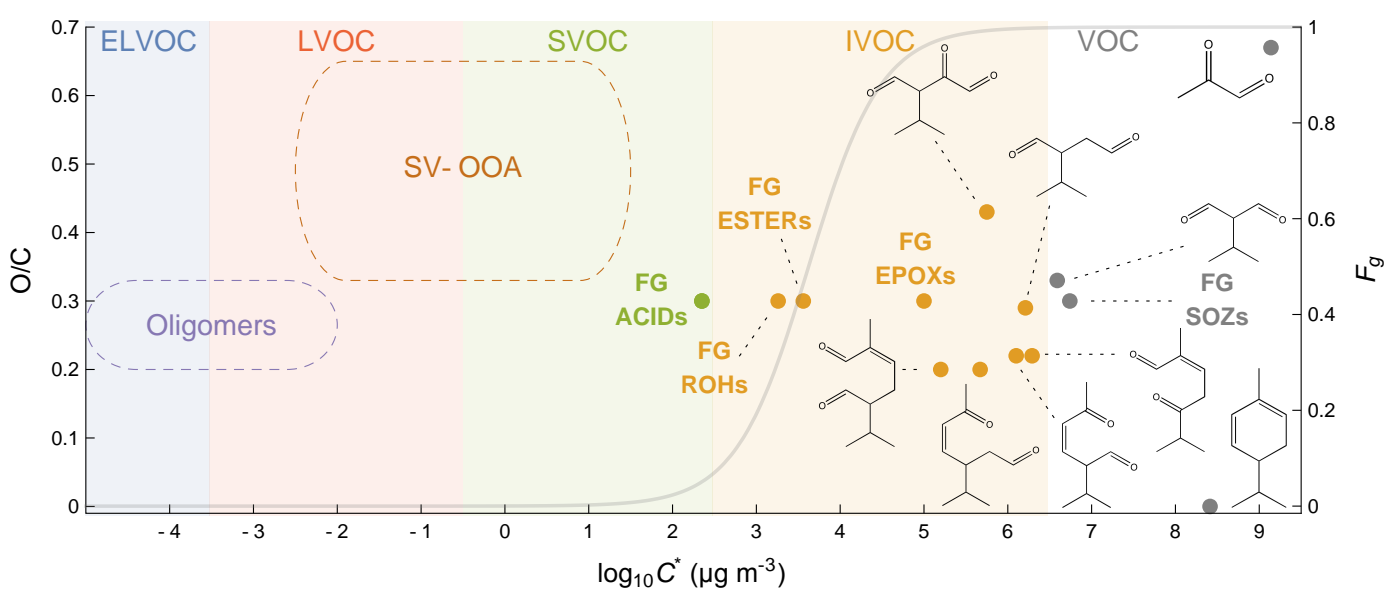

Figure 9. Dots show predicted first-generation and detected second-generation products from the ozonolysis of $\alpha$-phellandrene in Donahue et al. (2006) space. The grey line shows the fraction of species of different saturation vapour concentrations in the gas phase $\left(F_{\mathrm{g}}\right)$ after gas-wall and gas-particle equilibrium is reached, using $C_{\mathrm{W}}=5 \mathrm{mg} \mathrm{m}^{-3}$ and an SOA loading of $200 \mu \mathrm{g} \mathrm{m}^{-3}$. Formulation of $F_{\mathrm{g}}$ is given in the Supplement (Sect. S6).

out correcting for vapour wall losses, SOA yields are likely to be underestimated (Matsunaga and Ziemann, 2010; Zhang et al., 2014; La et al., 2016).

The majority of predicted first-generation and detected second-generation gas-phase products are classified as intermediate volatility compounds (IVOCs) (Donahue et al., 2012). As IVOCs, they are considered to have quite low vapour pressures but nonetheless reside almost exclusively in the gas phase. Of the proposed species, only the firstgeneration acids (e.g. Fig. 3) are classified as semi-volatile organic compounds (SVOCs), a classification given to those species which are expected to have sizeable mass fractions in the aerosol phase. Nevertheless, rapid aerosol formation is observed upon reaction of $\alpha$-phellandrene and ozone as shown in Fig. 10, with sharp increases in particle number $(\mathrm{d} N / \mathrm{d} \log \mathrm{Dp})$ and volume $(\mathrm{d} V / \mathrm{d} \log \mathrm{Dp})$ concentrations observed. With no aerosol seed, nucleation must be driven by supersaturation of condensible species formed in the initial stages of the reaction. Donahue et al. (2013) argue that nucleation occurs through compounds that have extremely low volatility (ELVOC, $C^{*}<3 \times 10^{-4} \mu \mathrm{g} \mathrm{m}^{-3}$ ). For the ozonolysis of other monoterpenes, ELVOC formation has been proposed to occur through gas-phase accretion reactions (Bateman et al., 2009; Heaton et al., 2009; Camredon et al., 2010) and autoxidation processes (Ehn et al., 2014; Jokinen et al., 2015). Meanwhile, to condense onto fresh aerosol but not homogeneously nucleate, vapours need to have saturation concentrations in the $10^{-3}-10^{-2} \mu \mathrm{g} \mathrm{m}^{-3}$ range (Donahue et al., 2011; Pierce et al., 2011), placing them in the lowvolatility organic compound bin. Formation of these compounds can be explained through conventional gas-phase chemistry (Donahue et al., 2011). It is therefore evident from Fig. 9 that the simple mechanistic overview provided to explain formation of gas-phase products in Sect. 3.1.1 and in
Mackenzie-Rae et al. (2016) is insufficient to account for aerosol observations, with more complex reactions or reaction processes such as autoxidation, oligomerisation and/or heterogeneous oxidation required to develop species of sufficiently low vapour pressure for both particle nucleation and growth (Hallquist et al., 2009).

The maximum number of particles inside the reactor occur within the first few minutes of the reaction commencing (time resolution of the SMPS), with a small average particle diameter $(\sim 40 \mathrm{~nm})$. Rapid nucleation is consistent with the findings of Jokinen et al. (2015), who, based on limonene and $\alpha$-pinene, concluded that endocyclic biogenic VOCs are efficient ELVOC producers upon ozonolysis. Coagulation of the newly formed aerosol decreases the number of particles, whilst further partitioning of low-volatility oxidation products increases the volume, with maximum aerosol concentration attained around $30 \mathrm{~min}$ into each experiment. After this point, irreversible wall losses supersedes gains from partitioning, with the volume, and hence mass, of aerosol decreasing inside the reactor.

In the early stages of experiments, the number concentration is a useful proxy for measuring the amount of nucleation occurring in the system (Bonn et al., 2002). As Fig. 11 shows, the addition of a Criegee scavenger systematically reduces initial particle number concentrations, concurrent with a shift of SOA to larger diameters. These changes suggest a reduction in the number of SOA-nucleating agents, implying that the reaction of $\alpha$-phellandrene sCIs is important in forming ELVOC and IVOC compounds, whilst ruling out the reaction of sCIs with formic acid as a nucleating mechanism. This finding is consistent with experimental literature that is now building around sCIs as a source of new particle formation, whether through intramolecular SOZ formation (Bonn et al., 2002), bimolecular reaction with first-generation prod- 

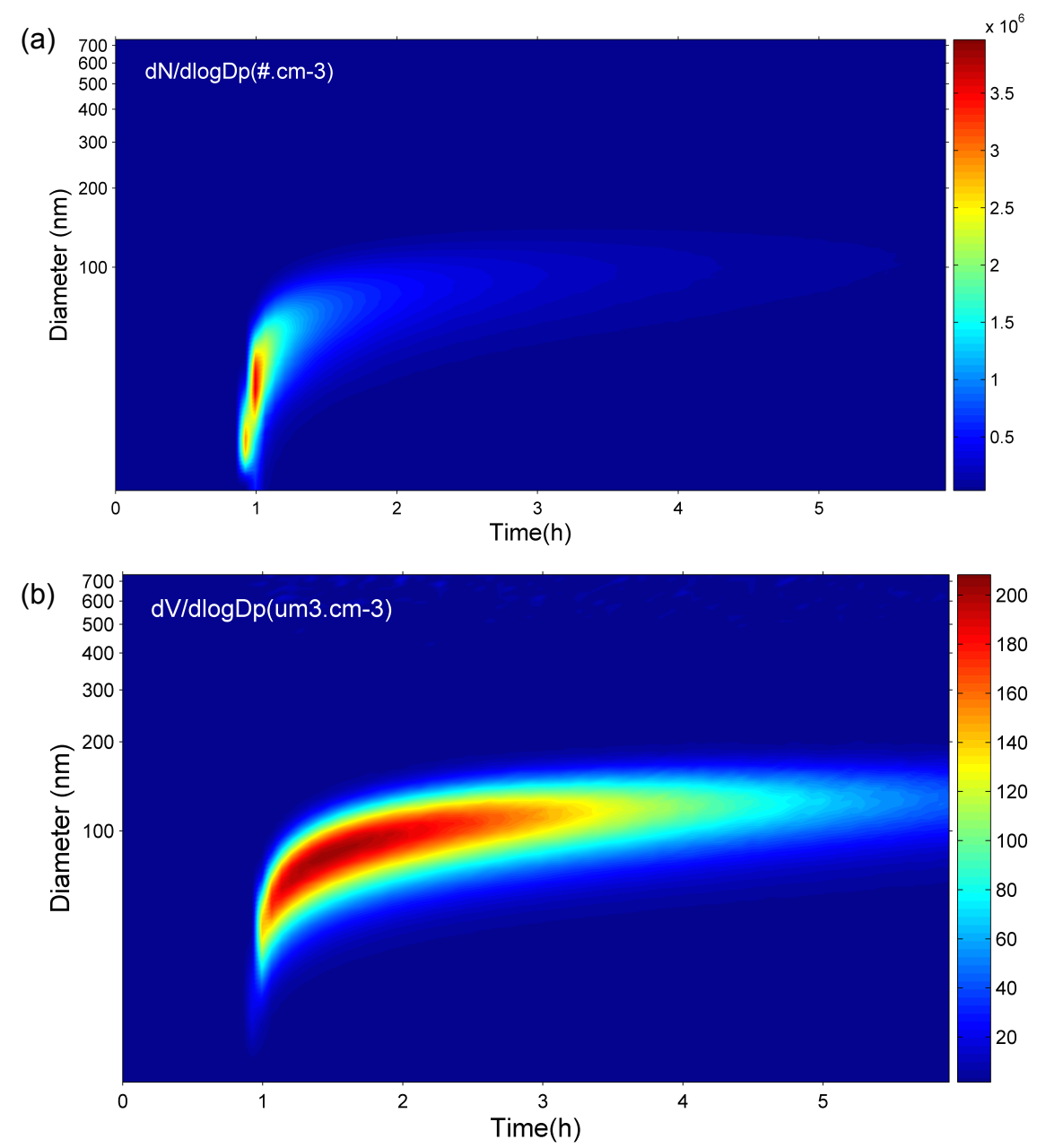

Figure 10. (a) Particle number $\left(\mathrm{cm}^{-3}\right)$ and (b) volume $\left(\mu \mathrm{m}^{3} \mathrm{~cm}^{-3}\right)$ size distributions for experiment 3 .

ucts (Bateman et al., 2009) or oligomer formation through reaction with peroxy radicals (Sadezky et al., 2006, 2008) or hydroperoxides (Sakamoto et al., 2013). Processes such as these would all be precluded by the addition of formic acid to the system. Similarly, there is a reduction in the $\alpha$ phellandrene normalised number distribution when $\mathrm{NO}_{2}$ is added (Fig. 11). Like formic acid, $\mathrm{NO}_{2}$ can also react with sCIs (Johnson and Marston, 2008) and therefore potentially inhibit particle formation and growth. If this were the case, then results from this ozonolysis study likely represent an upper limit to SOA formation under ambient conditions, although more experiments are necessary to confirm the impact of $\mathrm{NO}_{2}$ on $\mathrm{SOA}$ formation in the $\alpha$-phellandrene system.

Assuming spherical particles, effective aerosol densities were calculated by comparing distributions of vacuum aerodynamic and electric mobility diameters, using the AMS and SMPS, respectively (DeCarlo et al., 2004; Katrib et al., 2005). Results are listed in Table. The average density across all experiments was found to be $1.49 \pm 0.2 \mathrm{~g} \mathrm{~cm}^{-3}$, indicating that the aerosol exists in a solid or waxy state (Kostenidou et al., 2007). This value is consistent with the SOA density found in the ozonolysis of other monoterpenes under similar conditions, which typically ranges from 1.15 to $1.73 \mathrm{~g} \mathrm{~cm}^{-3}$ (Bahreini et al., 2005; Kostenidou et al., 2007; Saathoff et al., 2009; Shilling et al., 2009). Because the particles are potentially non-spherical, the quoted effective density represents a lower bound of the true $\alpha$-phellandrene SOA density, with error from assuming spherical particles expected to be less than $10 \%$ (DeCarlo et al., 2004; Bahreini et al., 2005). It is noted that the densest aerosol was produced in experiment 11, which had $\mathrm{NO}_{2}$ added, although one experiment is insufficient for reliable conclusions. The aerosol density was found to be insensitive to a range of other experimental parameters, including starting $\alpha$-phellandrene and ozone concentrations, aerosol loading, aerosol oxidation state and the presence of CI scavengers. These findings are in contrast to studies conducted on $\alpha$-pinene (Shilling et al., 2009) and $\beta$-caryophyllene (Chen et al., 2012), in which particle density was found to decrease as chamber aerosol loadings 


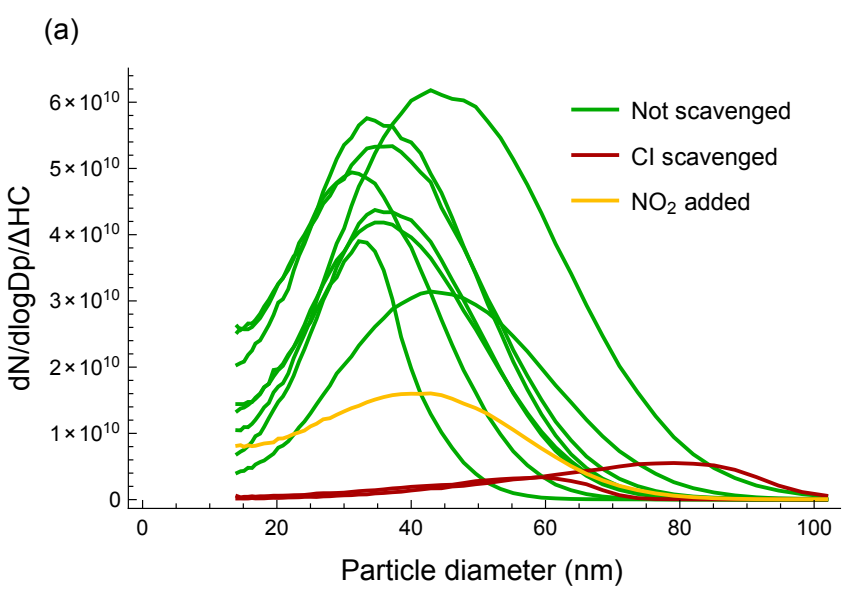

(b)

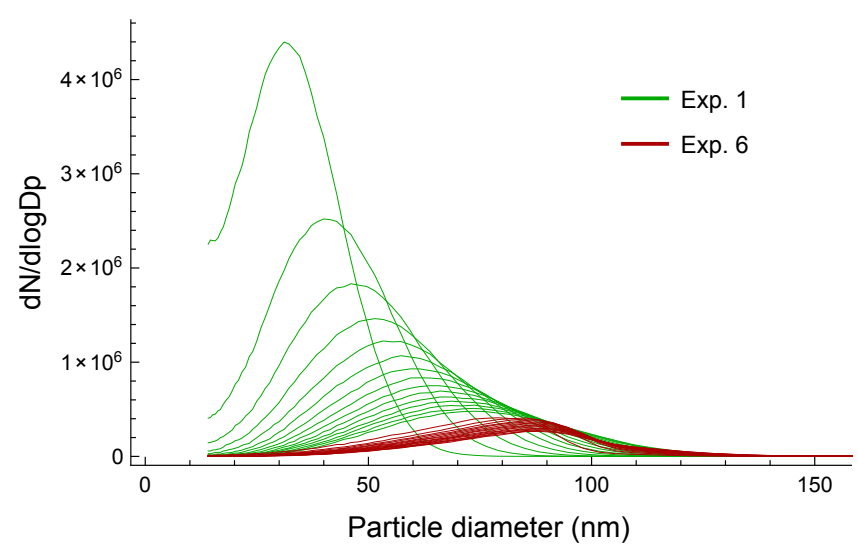

Figure 11. Impact of sCI scavengers on particle nucleation shown by (a) peak particle number distributions scaled for the amount of $\alpha$-phellandrene reacted in all experiments and (b) particle number distributions evolution over the first hour of experiments 1 and 6 .

increased, in accordance with changes in aerosol oxidation state.

Aerosol densities were used to convert SMPS volume concentrations into mass loadings $\left(\mu \mathrm{g} \mathrm{m}^{-3}\right)$. Wall loss effects were corrected for by assuming a size-independent firstorder loss process (Pathak et al., 2007), by modelling data at the end of each experiment, after gas-aerosol partitioning had reached equilibrium. Calculated wall loss rate constants, which ranged from 0.32 to $0.79 \mathrm{~h}^{-1}$, were then applied to correct mass loading data for respective experiments. This way, differences between individual chamber simulations are accounted for. Determined wall loss rates are consistent with those found for $\alpha$-pinene ozonolysis in the chamber (Wang et al., 2014).

The same method was used to correct V-mode AMS data, with results given in the Supplement (Sect. S7). Clustering of points around the 1:1 line in Fig. S7.1 indicates general agreement between mass loadings calculated using the AMS and SMPS (Shilling et al., 2008). Nevertheless, densitycorrected SMPS data is preferred in this work, primarily be-
Table 6. Aerosol loadings, effective densities, oxidation states and yields for $\alpha$-phellandrene ozonolysis experiments.

\begin{tabular}{lrrrr}
\hline No. & $\begin{array}{r}\text { Total SOA } \\
\text { mass }^{*}\left(\mu \mathrm{g} \mathrm{m}^{3}\right)\end{array}$ & $\begin{array}{r}\text { Density } \\
\left(\mathrm{g} \mathrm{cm}^{-3}\right)\end{array}$ & $\overline{\mathrm{OS}}_{\mathrm{c}}$ & $\begin{array}{r}\text { Yield } \\
(Y)\end{array}$ \\
\hline 1 & $86.1 \pm 9$ & $1.29 \pm 0.05$ & $-0.91 \pm 0.3$ & $0.81 \pm 0.3$ \\
2 & $21.5 \pm 2$ & $1.32 \pm 0.06$ & $-0.65 \pm 0.2$ & $0.37 \pm 0.2$ \\
3 & $121.3 \pm 13$ & $1.37 \pm 0.05$ & $-0.93 \pm 0.3$ & $1.03 \pm 0.4$ \\
4 & $311.9 \pm 33$ & $1.57 \pm 0.05$ & $-0.93 \pm 0.3$ & $1.74 \pm 0.7$ \\
5 & $178.0 \pm 19$ & $1.36 \pm 0.05$ & $-1.0 \pm 0.3$ & $1.11 \pm 0.5$ \\
6 & $52.0 \pm 6$ & $1.38 \pm 0.05$ & $-0.77 \pm 0.3$ & $0.60 \pm 0.2$ \\
7 & $27.6 \pm 3$ & $1.34 \pm 0.05$ & $-0.63 \pm 0.2$ & $0.25 \pm 0.1$ \\
8 & $199.7 \pm 21$ & $1.69 \pm 0.06$ & $-0.82 \pm 0.3$ & $0.72 \pm 0.3$ \\
9 & $341.0 \pm 36$ & $1.61 \pm 0.05$ & $-0.83 \pm 0.3$ & $0.90 \pm 0.37$ \\
10 & $658.1 \pm 70$ & $1.60 \pm 0.05$ & $-0.99 \pm 0.3$ & $0.71 \pm 0.3$ \\
11 & $504.9 \pm 53$ & $1.90 \pm 0.06$ & $-1.0 \pm 0.3$ & $1.02 \pm 0.4$ \\
\hline$*$
\end{tabular}

* Wall-loss corrected (Pathak et al., 2007).

cause the AMS is known to suffer from transmission losses caused by particles bouncing off the vaporiser and, to a lesser extent, shape-dependent collection losses whilst focusing the particle beam (Matthew et al., 2008; Slowik et al., 2004; Huffman et al., 2005). Whilst it is noted that the SMPS does not measure particles with diameters larger than $750 \mathrm{~nm}$, as shown in Fig. 10, this shortcoming is expected to have minimal impact on reported yields in this work (Wiedensohler et al., 2012).

Wall-loss-corrected mass loadings for each experiment are given in Table, along with fractional aerosol yields $(Y)$. The fractional aerosol yield is defined as the amount of organic particulate matter that is produced $\left(\Delta M_{\mathrm{o}}, \mu \mathrm{g} \mathrm{m}^{-3}\right)$ for a given amount of precursor VOC reacted $\left(\triangle \mathrm{HC}, \mu \mathrm{g} \mathrm{m}^{-3}\right.$ ) (Odum et al., 1996) and provides a convenient way of assessing the bulk aerosol-forming potential of an individual VOC. Utilising the gas-particle partitioning framework, aerosol yield can be described as a function of organic aerosol mass concentration (Pankow, 1994; Odum et al., 1996):

$Y=\frac{\Delta M_{\mathrm{o}}}{\Delta \mathrm{HC}}=\Delta M_{\mathrm{o}} \sum_{i} \frac{\alpha_{i} K_{\mathrm{om}, i}}{1+K_{\mathrm{om}, i} \Delta M_{\mathrm{o}}}$,

where $\alpha_{i}$ is the stoichiometric factor and $K_{\mathrm{om}, i}$ the temperature-dependent equilibrium-partitioning constant of product $i$.

A characteristic yield plot is given in Fig. 12. Whilst a large number of products are expected to contribute to the particle phase, SOA yield is best fit using the parameters $\alpha_{1}=1.2 \pm 0.2$ and $K_{\mathrm{om}, 1}=0.022 \pm 0.02 \mathrm{~m}^{3} \mu \mathrm{g}^{-1}$, with higher-order fits found to be superfluous. The fitted constants offer little physical insight, other than perhaps the average of all $\alpha$ and $K_{\text {om }}$ values but nonetheless can be used in regional and global modelling (Chung and Seinfeld, 2002; Tsigaridis and Kanakidou, 2003; Henze and Seinfeld, 2006; Jathar et al., 2016). 


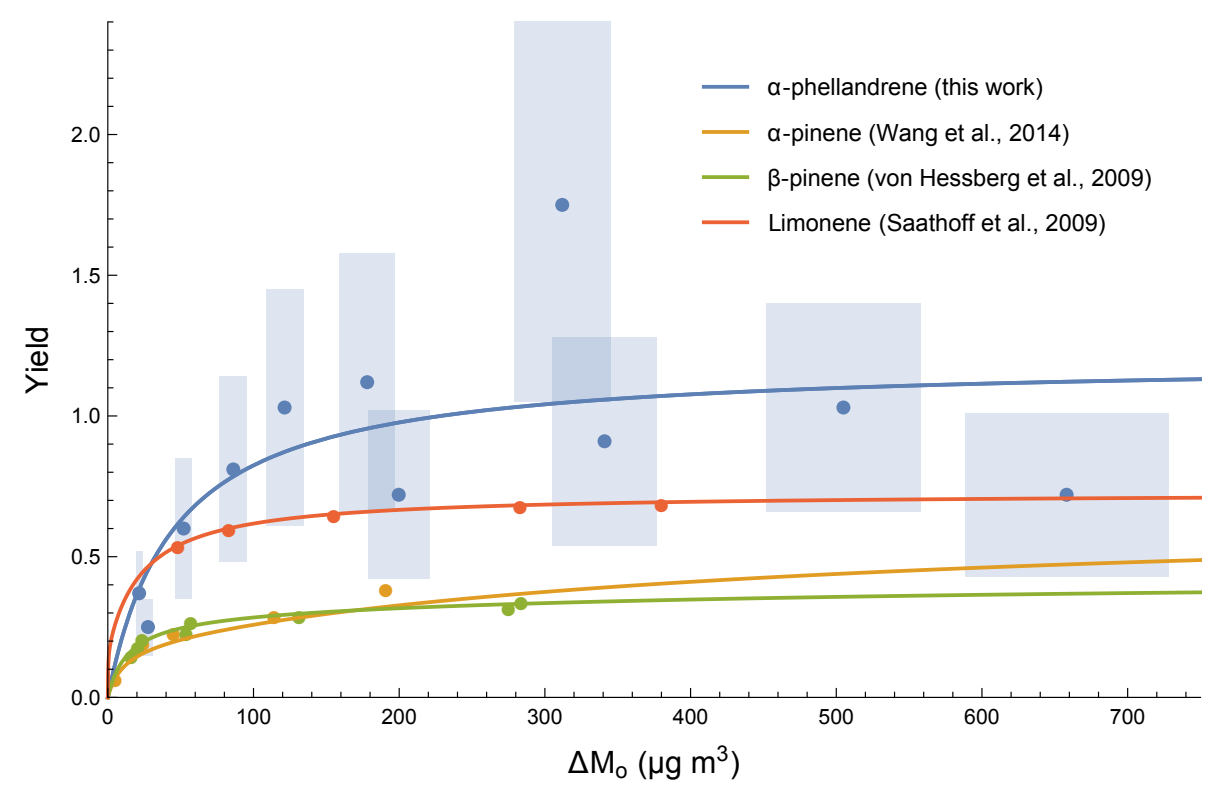

Figure 12. Comparison of SOA yield data for $\alpha$-phellandrene with other monoterpene ozonolysis experiments. Lines are the best empirical model fits (Odum et al., 1996).

Figure 12 shows that $\alpha$-phellandrene produces a large amount of aerosol upon ozonolysis compared to other monoterpenes (Wang et al., 2014; Saathoff et al., 2009; von Hessberg et al., 2009). Formation of the necessary semivolatile organic compounds is likely driven by the presence of two highly reactive endocyclic double bonds, with functionalisation rather than fragmentation dominating for the first addition (Lee et al., 2006). Both experiments where a CI scavenger was added lie below the fitted yield curve, strengthening the argument for sCIs as a source of condensible products. Nevertheless, yields from the two experiments differ by almost a factor of 2 despite having similar starting conditions, with further experiments necessary to better quantify the impact of sCIs on yields. Cyclohexane has been shown to reduce SOA yields in ozonolysis experiments (Bonn et al., 2002; Keywood et al., 2004; Saathoff et al., 2009), although no such effects were observed in this study.

The second addition of ozone, in general, fragments the molecule but in doing so increases relative oxygen content. Thus, the relative contribution of first- and second-generation products to SOA is empirically difficult to predict. Figure 13 shows SOA mass as a function of $\alpha$-phellandrene reacted, producing time-dependent aerosol growth curves. In all experiments where $\alpha$-phellandrene was completely consumed, dominant vertical growth profiles are traced. This increase in aerosol mass after complete consumption of parent hydrocarbon is characteristic of compounds with more than one double bond ( $\mathrm{Ng}$ et al., 2006) and suggests that, when formed, second-generation products make an important contribution to the total aerosol mass. It is therefore likely that a large number of second-generation species fall in the IVOC or SVOC category in Fig. 9.

Whilst concentrations of precursors are somewhat elevated in experiments compared to ambient conditions, results nonetheless show $\alpha$-phellandrene ozonolysis products to be heavily involved in both particle nucleation and growth processes. In polluted environments (e.g. inner-city forests, consumer products), a high SOA yield results in a large fraction of $\alpha$-phellandrene partitioning into the particle phase irrespective of gas-phase loadings. Meanwhile, a strong nucleation potential makes $\alpha$-phellandrene ozonolysis a strong candidate to help explain the intense and frequent nocturnal nucleation events observed in Eucalypt forests (Lee et al., 2008; Suni et al., 2008), which are already believed to be caused by monoterpene oxidation products (Ortega et al., 2009, 2012). Indeed, the reaction conditions used in these experiments better reflect this clean environment, where reactions of $\mathrm{RO}_{2}$ with $\mathrm{HO}_{2}$ and other $\mathrm{RO}_{2}$ radicals dominate along with unimolecular rearrangements. Such conditions favour the formation of low-volatility compounds, with the highest SOA yields for monoterpenes found under low$\mathrm{NO}_{x}$ conditions (Presto et al., 2005; Ng et al., 2007; Capouet et al., 2008; Eddingsaas et al., 2012). Under these conditions, ozonolysis reactions remain important (Perraud et al., 2012; Zhao et al., 2015), which is conducive to autoxidation processes and therefore nascent SOA formation and growth due to enhanced propensity for intramolecular rearrangements (Ehn et al., 2014; Jokinen et al., 2015). SOA yields measured in experiment 11 are consistent, however, with the other ozonolysis experiments in this study (Fig. 12), suggesting that the impact of $\mathrm{NO}_{x}$ on SOA yields during the 


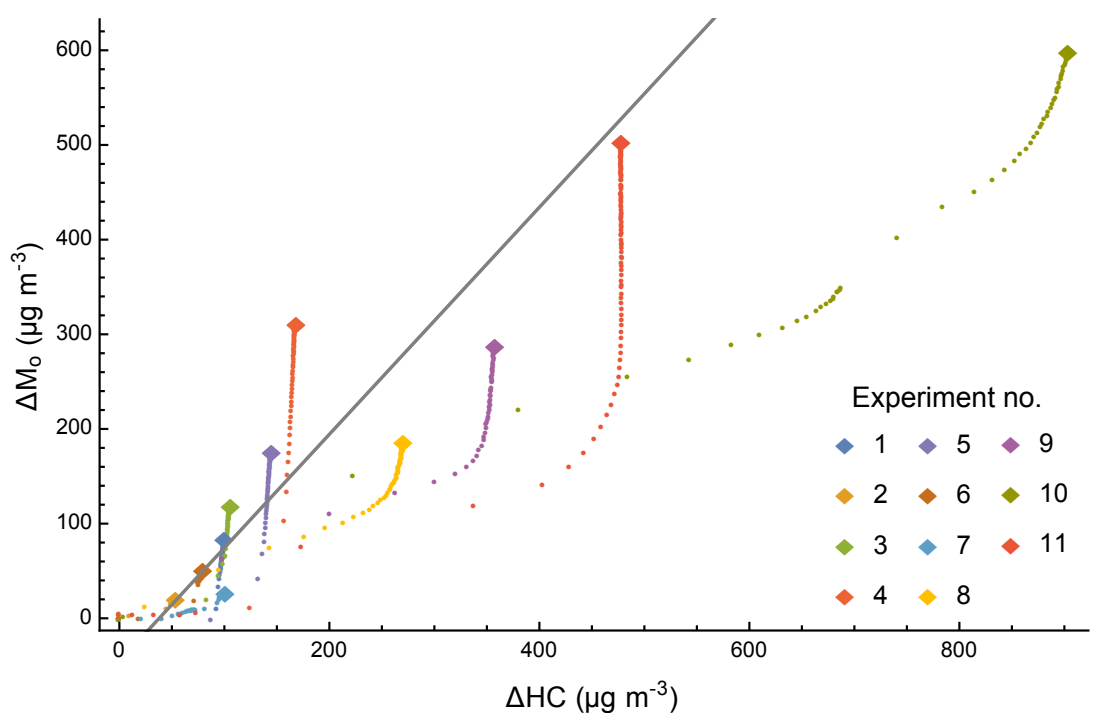

Figure 13. Time-dependent SOA growth curves. The grey line is a fitted one-parameter fit yield curve.

ozonolysis of $\alpha$-phellandrene is limited, with sufficient condensible products still able to be produced (Draper et al., 2015). Nonetheless, the reduction in aerosol number concentration in the initial stages of experiment 11 does suggest that formation pathways of ELVOC species (i.e. oligomerisation, autoxidation) are suppressed by the inclusion of $\mathrm{NO}_{2}$ (Perraud et al., 2012). Detailed modelling studies are required to establish the relative importance of $\alpha$-phellandrene in different environments, although evidence suggests that it is likely a contributor to nucleation events and aerosol growth in regions where it is emitted.

\subsubsection{SOA composition}

Resolution in the W mode of the AMS is sufficient to unambiguously identify chemical formulae of detected ions (DeCarlo et al., 2006; Aiken et al., 2007). Ions are formed, however, using high-energy electron impact ionisation $(70 \mathrm{eV})$, resulting in significant fragmentation. The complexity of aerosol produced, along with an unknown number of fragmentation pathways, including the possibility of charge migration and other internal rearrangements, makes it exceedingly difficult to obtain clear structural information about SOA constituents from the AMS. For this reason, filter samples were collected and analysed to identify SOA constituents, with results to be published in a companion paper. Nevertheless, the AMS remains useful for analysing bulk properties of the aerosol to gain further insight into the system.

Bulk elemental composition can be estimated by averaging ion contributions across the entire mass spectrum (Aiken et al., 2007). Raw measured atomic ratios are converted to estimated ratios using the calibration factors of Aiken et al. (2008), namely $0.91 \pm 10 \%$ for hydrogen-to-carbon (H / C),

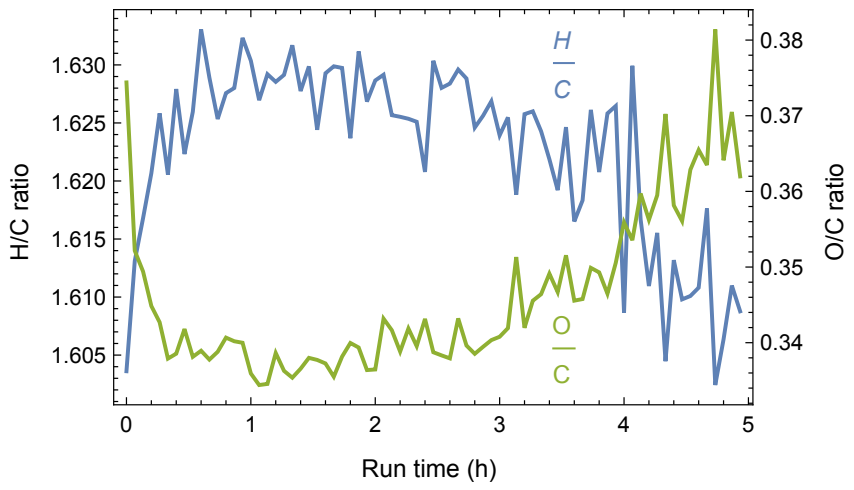

Figure 14. $\mathrm{H} / \mathrm{C}$ and $\mathrm{O} / \mathrm{C}$ ratios as a function of time for a typical $\alpha$-phellandrene ozonolysis experiment (experiment 4).

$0.75 \pm 31 \%$ for oxygen-to-carbon $(\mathrm{O} / \mathrm{C})$ and $0.96 \pm 22 \%$ for nitrogen-to-carbon ratios, respectively, thus accounting for chemical biases in fragmentation.

Figure 14 shows the typical temporal profile of aerosol composition observed over an experiment. Initial aerosol formation and growth is driven by highly oxygenated species; however, as the organic aerosol (OA) medium grows and less functionalised species begin to partition, the overall oxidation state rapidly decreases, as seen by a drop in $\mathrm{O} / \mathrm{C}$ and respective rise in $\mathrm{H} / \mathrm{C}$ ratios. Once gas-particle partitioning slows and aerosol-loss processes dominate, there is a shift in equilibrium, with the more volatile aerosol constituents evaporating back into the gaseous phase. It can therefore be concluded that many of the SOA products generated during the chamber ozonolysis of $\alpha$-phellandrene in this study are semi-volatile (Donahue et al., 2012). Nitrogen-containing species were found to make little contribution to the aerosol formed in experiment 11 , with an average $\mathrm{N} / \mathrm{C} \approx 0.002$ dur- 
ing the experiment. Nitrate and PAN functionality is believed to significantly reduce the vapour pressure of constituents (Capouet and Müller, 2006; Pankow and Asher, 2008), with the result implying a small gas-phase concentration. Nevertheless, there exists evidence that organic nitrate contribution to SOA may be kinetically driven, rather than volatility driven (Perraud et al., 2012).

The average oxidation state of carbon $\left(\overline{\mathrm{OS}}_{\mathrm{c}}\right)$ in aerosol comprising of carbon, hydrogen and oxygen was parameterised by Kroll et al. (2011) as

$\overline{\mathrm{OS}}_{\mathrm{c}} \approx 2 \mathrm{O} / \mathrm{C}-\mathrm{H} / \mathrm{C}$.

Although the definition ignores the effects of peroxides, whose oxygen atoms carry an oxidation state of -1 , it nonetheless serves as a useful metric for representing the degree of oxidation of organic species in complex aerosol mixtures. Figure 15 shows that $\overline{\mathrm{OS}}_{\mathrm{c}}$ decreases from -0.61 to -1.00 as the particle loading increases from 21.5 to $658.1 \mu \mathrm{g} \mathrm{m}^{-3}$, suggesting a strong link between mass loading and degree of functionalisation, consistent with the findings of Shilling et al. (2009) for the ozonolysis of $\alpha$-pinene. The fastest change in $\overline{\mathrm{OS}}_{\mathrm{c}}$ is observed to occur at lower mass loadings. Calculated $\overline{\mathrm{OS}}_{\mathrm{c}}$ classifies the aerosol formed throughout the campaign as semi-volatile oxygenated organic aerosol (SV-OOA) (Kroll et al., 2011), consistent with numerous monoterpene and $\mathrm{O}_{3}$ chamber experiments (Bateman et al., 2009; Aiken et al., 2008; Shilling et al., 2009; Chhabra et al., 2010; Chen et al., 2011). SOA density predictions from elemental ratios using the parameterisation of Kuwata et al. (2012) show some agreement with measured values (Supplement Sect. S8).

A van Krevelen plot of the entire dataset is given in Fig. 16. The impact of $\mathrm{CI}$ scavengers, cyclohexane and $\mathrm{NO}_{2}$ on $\mathrm{OA}$ in van Krevelen space is observed to be minor. The important parameter was found to be aerosol mass loadings, with changes resulting in vertical shifts consistent with a change in oxidation state. Ozonolysis reactions are unique, as oxygen can be added and condensible products formed with no loss (and possibly gain) of hydrogen. Because of this, generic functionalisation lines used to characterise reactions in van Krevelen space (Heald et al., 2010; Chhabra et al., 2011) are not applicable.

It is evident from Fig. 16 that the majority of predicted species have a lower $\mathrm{O} / \mathrm{C}$ ratio compared to what is measured for the bulk of the aerosol. It is therefore unlikely that any of the detected gas-phase species are substantially contributing to the generated aerosol, which instead is dominated by more functionalised products. Whilst it is likely that species comprising the OA are also present in the gas phase, they exist below the detection threshold of, or are lost in detection by, the PTR-TOF. Indeed, the presence of a filter prior to the PTR-TOF inlet may hinder detection of less volatile species, as elevated levels of OA on the filter may coax species into partitioning (Turpin et al., 2000; Kirchstetter et al., 2001).

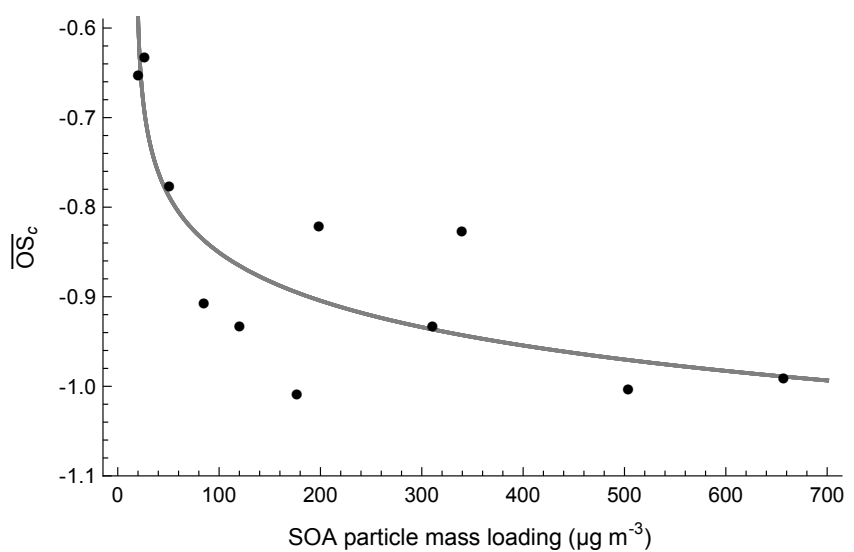

Figure 15. Average oxidation state of carbon for increasing SOA loadings generated through $\alpha$-phellandrene ozonolysis experiments, with the general trend shown.

The carbon mass balance for each experiment is shown in Fig. 17. It was calculated by summing the gas-phase yields of all product ions, assuming a carbon number of 6 for unidentified products, with SOA yields, whose carbon content was determined from elemental ratios measured in each experiment. The carbon balance ranged from 25 to $131 \%$. General losses in the system, such as vapour losses to the Teflon walls, affect the ability to close the carbon mass balance for most experiments, with performance worse in those experiments with lower starting $\alpha$-phellandrene concentrations due to an inability to detect minor gas-phase products. It is evident from Fig. 17 that, despite having lower yields, heavier gas-phase products make a larger contribution to the carbon mass balance than lighter species such as formaldehyde, glyoxal, formic acid and acetic acid, whose nominal yields are higher. Meanwhile, experiment 4 had a carbon mass balance exceeding $100 \%$, which is thought to be the result of an erroneously high SOA yield (Fig. 12). It is immediately obvious from the carbon mass balances that a large fraction of $\alpha$ phellandrene partitions into the aerosol phase upon ozonolysis, exemplifying the impact $\alpha$-phellandrene can have on SOA formation and growth. Currently, the species comprising SOA generated from $\alpha$-phellandrene ozonolysis remains unidentified; however, a complete analysis of filter samples collected during these experiments is underway, in preparation for a follow-on publication.

\section{Conclusions}

The reaction of $\alpha$-phellandrene with ozone was studied in depth for the first time through 11 chamber experiments. In the gas phase, only signals with increasing temporal profiles were detected by the PTR-TOF, indicative of secondgeneration products. Of these, small species $\left(\leq \mathrm{C}_{3}\right)$ were found to be produced in the highest yields, namely formaldehyde $(5-9 \%)$, acetaldehyde $(0.2-8 \%)$, glyoxal (6-23\%), 


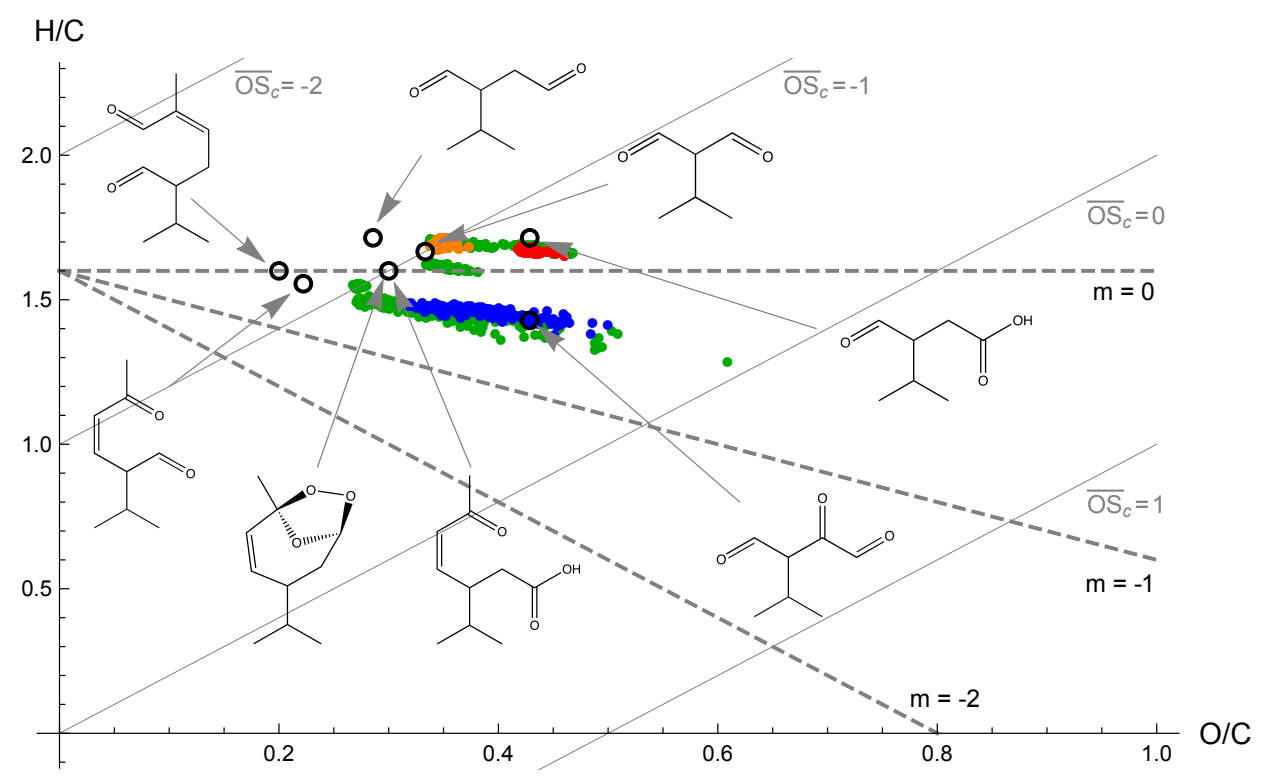

Figure 16. Van Krevelen plot. Blue dots are for experiments with a CI scavenger $(6,7)$, red dots are for the experiment without cyclohexane (9), yellow dots are for the experiment with $\mathrm{NO}_{2}$ added (11) and green dots are for the remaining experiments. Both predicted and detected gas-phase species are shown with open black circles.

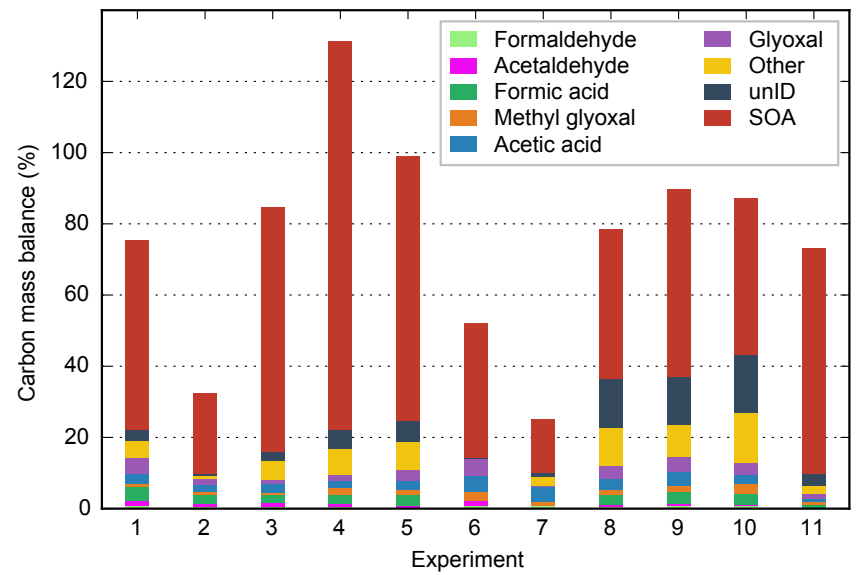

Figure 17. Carbon mass balance for each experiment.

methyl glyoxal (2-9\%), formic acid (22-37\%) and acetic acid $(9-22 \%)$, with yields of all products suppressed by the addition of $\mathrm{NO}_{2}$. Despite having lower yields, heavier second-generation products were found to make a larger contribution to the carbon mass balance. A small number of second-generation products were tentatively identified based on a constructed gas-phase mechanism, including 2-propan-2-ylpropanedial and 2-propan-2-ylbutanedial. Experimental $\mathrm{OH}$-radical yields of $35 \pm 12 \%$ and $15 \pm 7 \%$ for $\alpha$-phellandrene and its first-generation products are in good agreement with those reported in Herrmann et al. (2010) and show the hydroperoxide channel to be an important pathway, with model output from a simple reaction pa- rameterisation suggesting experimental yields to be a lower bound. Meanwhile, modelling provides a rate coefficient of $1.0 \pm 0.7 \times 10^{-16} \mathrm{~cm}^{3}$ molecule $\mathrm{s}^{-1}$ for the average reaction of first-generation products with ozone at $298 \mathrm{~K}$. This equates to an atmospheric lifetime of around $3.75 \mathrm{~h}$, higher than many other monoterpenes, and suggests that complete saturation of $\alpha$-phellandrene likely occurs in the environment to which it is emitted.

$\alpha$-phellandrene was found to form a large amount of aerosol upon reacting with ozone. A homogeneous nucleation burst of fresh aerosol was observed in all experiments within the first few minutes of the reaction, indicating a rapid formation of ELVOC species. Addition of a CI scavenger inhibited nucleation, suggesting that sCIs are important precursors in forming compounds of low volatility in the system. The mechanism behind this remains unknown, although numerous pathways have been proposed in the literature for CIs from other alkenes with more experiments required. Addition of $\mathrm{NO}_{2}$ was found to reduce initial nucleation, although overall yields remained the same. The average effective SOA density was determined to be $1.49 \pm 0.2 \mathrm{~g} \mathrm{~cm}^{-3}$ with an oxidation state varying from 0.56 to 1.02 depending on mass loadings. SOA growth curves show both first- and secondgeneration species contribute to the particulate phase, driving aerosol growth through to completion of the reaction. SOA yield is best fit by a one-product model with $\alpha_{1}=1.2 \pm 0.2$ and $K_{\mathrm{om}, 1}=0.022 \pm 0.02 \mathrm{~m}^{3} \mathrm{\mu g}^{-1}$, with the SOA-forming potential from $\alpha$-phellandrene ozonolysis greater than other monoterpenes previously investigated in the literature. 
High radical, acid and SOA yields, coupled with a high reactivity, result in $\alpha$-phellandrene having an immediate and significant impact on its local environment. Indeed, it appears likely that ozonolysis of $\alpha$-phellandrene contributes to the significant blue haze and intense and frequent nocturnal nucleation events observed over Eucalypt forests. Characterisation and parameterisation of both the gaseous and particle phases formed from the ozonolysis of $\alpha$-phellandrene therefore better our understanding of the impact of biogenic emissions and begin to enable the inclusion of this potentially important monoterpene in future atmospheric models.

Data availability. A website dedicated to the smog chamber is currently under construction and will include all chamber data. In the meantime, original data pertaining to this work can be obtained upon request from Xinming Wang (wangxm@gig.ac.cn).

\section{The Supplement related to this article is available online at https://doi.org/10.5194/acp-17-6583-2017-supplement.}

Competing interests. The authors declare that they have no conflict of interest.

Acknowledgements. Experiments were made possible through funding by the Strategic Priority Research Program of the Chinese Academy of Sciences (grant no. XDB05010200), Ministry of Science and Technology of China (grant no. 2016YFC0202204) and National Natural Science Foundation of China (grant no. 41530641/41571130031). The authors would also like to extend their thanks to Antoinette Boreave (IRCELYON) for assistance with operating the AMS.

Edited by: M. Petters

Reviewed by: two anonymous referees

\section{References}

Aiken, A. C., DeCarlo, P. F., and Jimenez, J. L.: Elemental analysis of organic species with electron ionization highresolution mass spectrometry, Anal. Chem., 79, 8350-8358, https://doi.org/10.1029/2010GL042737, 2007.

Aiken, A. C., Decarlo, P. F., Kroll, J. H., Worsnop, D. R., Huffman, J. A., Docherty, K. S., Ulbrich, I. M., Mohr, C., Kimmel, J. R., Sueper, D., Sun, Y., Zhang, Q., Trimborn, A., Northway, M., Ziemann, P. J., Canagaratna, M. R., Onasch, T. B., Alfarra, M. R., Prévôt, A. S. H., Dommen, J., Duplissy, J., Metzger, A., Baltensperger, U., and Jimenez, J. L.: $\mathrm{O} / \mathrm{C}$ and $\mathrm{OM} / \mathrm{OC}$ ratios of primary, secondary, and ambient organic aerosols with high-resolution time-of-flight aerosol mass spectrometry, Environ. Sci. Technol., 42, 4478-4485, https://doi.org/10.1021/es703009q, 2008.

Aoki, N., Inomata, S., and Tanimoto, H.: Detection of $\mathrm{C}_{1}-$ $\mathrm{C}_{5}$ alkyl nitrates by proton transfer reaction time-of-flight mass spectrometry, Int. J. Mass Spectrom., 263, 12-21, https://doi.org/10.1016/j.ijms.2006.11.018, 2007.

Aschmann, S. M. and Atkinson, R.: Formation yields of methyl vinyl ketone and methacrolein from the gas-phase reaction of $\mathrm{O}_{3}$ with isoprene, Environ. Sci. Technol., 28, 1539-1542, https://doi.org/10.1021/es00057a025, 1994.

Aschmann, S. M., Arey, J., and Atkinson, R.: OH radical formation from the gas-phase reactions of $\mathrm{O}_{3}$ with methacrolein and methyl vinyl ketone, Atmos. Environ., 30, 2939-2943, https://doi.org/10.1016/1352-2310(96)00013-1, 1996.

Atkinson, R. and Arey, J.: Gas-phase tropospheric chemistry of biogenic volatile organic compounds: A review, Atmos. Environ., 37, S197-S219, https://doi.org/10.1016/S1352-2310(03)00391$1,2003$.

Atkinson, R., Hasegawa, D., and Aschmann, S. M.: Rate constants for the gas-phase reactions of $\mathrm{O}_{3}$ with a series of monoterpenes and related compounds at $296 \pm 2 \mathrm{~K}$, Int. J. Chem. Kinet., 22, 871-887, https://doi.org/10.1002/kin.550220807, 1990.

Atkinson, R., Aschmann, S. M., Arey, J., and Shorees, B.: Formation of $\mathrm{OH}$ radicals in the gas phase reactions of $\mathrm{O}_{3}$ with a series of terpenes, J. Geophys. Res., 97, 6065-6073, https://doi.org/10.1029/92JD00062, 1992.

Atkinson, R., Baulch, D. L., Cox, R. A., Crowley, J. N., Hampson, R. F., Hynes, R. G., Jenkin, M. E., Rossi, M. J., and Troe, J.: Evaluated kinetic and photochemical data for atmospheric chemistry: Volume $\mathrm{I}-$ gas phase reactions of $\mathrm{O}_{x}, \mathrm{HO}_{x}$, $\mathrm{NO}_{x}$ and $\mathrm{SO}_{x}$ species, Atmos. Chem. Phys., 4, 1461-1738, https://doi.org/10.5194/acp-4-1461-2004, 2004.

Bahreini, R., Keywood, M. D., Ng, N. L., Varutbangkul, V., Gao, S., Flagan, R. C., Seinfeld, J. H., Worsnop, D. R., and Jimenez, J. L.: Measurements of secondary organic aerosol from oxidation of cycloalkenes, terpenes, and $m$-xylene using an aerodyne aerosol mass spectrometer, Environ. Sci. Technol., 39, 56745688, https://doi.org/10.1021/es048061a, 2005.

Barley, M. H. and McFiggans, G.: The critical assessment of vapour pressure estimation methods for use in modelling the formation of atmospheric organic aerosol, Atmos. Chem. Phys., 10, 749767, https://doi.org/10.5194/acp-10-749-2010, 2010.

Bateman, A. P., Nizkorodov, S. A., Laskin, J., and Laskin, A.: Time-resolved molecular characterization of limonene/ozone aerosol using high-resolution electrospray ionization mass spectrometry, Phys. Chem. Chem. Phys., 11, 7931-7942, https://doi.org/10.1039/b916865f, 2009.

Berndt, T., Böge, O., and Stratmann, F.: Gas-phase ozonolysis of $\alpha$-pinene: gaseous products and particle formation, Atmos. Environ., 37, 3933-3945, https://doi.org/10.1016/S13522310(03)00501-6, 2003.

Blake, R. S., Wyche, K. P., Ellis, A. M., and Monks, P. S.: Chemical ionization reaction time-of-flight mass spectrometry: Multi-reagent analysis for determination of trace gas composition, Int. J. Mass Spectrom., 254, 85-93, https://doi.org/10.1016/j.ijms.2006.05.021, 2006.

Bonn, B., Schuster, G., and Moortgat, G. K.: Influence of water vapor on the process of new particle formation during monoterpene ozonolysis, J. Phys. Chem. A, 106, 2869-2881, https://doi.org/10.1021/jp012713p, 2002.

Brophy, J. J. and Southwell, I. A.: Eucalyptus Chemistry, in: Eucalyptus: The Genus Eucalyptus, Taylor \& Francis, London, UK, 2002. 
Calvert, J. G., Atkinson, R., Kerr, J. A., Madronich, S., Moortgat, G. K., Wallington, T. J., and Yarwood, G.: The Mechanisms of Atmospheric Oxidation of the Alkenes, Oxford University Press, Oxford, UK, 2000

Camredon, M., Hamilton, J. F., Alam, M. S., Wyche, K. P., Carr, T., White, I. R., Monks, P. S., Rickard, A. R., and Bloss, W. J.: Distribution of gaseous and particulate organic composition during dark $\alpha$-pinene ozonolysis, Atmos. Chem. Phys., 10, 2893-2917, https://doi.org/10.5194/acp-10-2893-2010, 2010.

Capouet, M. and Müller, J.-F.: A group contribution method for estimating the vapour pressures of $\alpha$-pinene oxidation products, Atmos. Chem. Phys., 6, 1455-1467, https://doi.org/10.5194/acp-61455-2006, 2006.

Capouet, M., Müller, J.-F., Ceulemans, K., Compernolle, S., Vereecken, L., and Peeters, J.: Modeling aerosol formation in alpha-pinene photo-oxidation experiments, J. Geophys. Res., 113, D02308, https://doi.org/10.1029/2007JD008995, 2008.

Cappellin, L., Karl, T., Probst, M., Ismailova, O., Winkler, P. M., Soukoulis, C., Aprea, E., Märk, T. D., Gasperi, F., and Biasioli, F.: On quantitative determination of volatile organic compound concentrations using proton transfer reaction time-offlight mass spectrometry., Environ. Sci. Technol., 46, 2283-90, https://doi.org/10.1021/es203985t, 2012.

Chen, Q., Liu, Y., Donahue, N. M., Shilling, J. E., and Martin, S. T.: Particle-phase chemistry of secondary organic material: Modeled compared to measured $\mathrm{O}: \mathrm{C}$ and $\mathrm{H}: \mathrm{C}$ Elemental ratios provide constraints, Environ. Sci. Technol., 45, 4763-4770, https://doi.org/10.1021/es104398s, 2011.

Chen, Q., Li, Y. L., McKinney, K. A., Kuwata, M., and Martin, S. T.: Particle mass yield from $\beta$-caryophyllene ozonolysis, Atmos. Chem. Phys., 12, 3165-3179, https://doi.org/10.5194/acp12-3165-2012, 2012.

Chhabra, P. S., Flagan, R. C., and Seinfeld, J. H.: Elemental analysis of chamber organic aerosol using an aerodyne high-resolution aerosol mass spectrometer, Atmos. Chem. Phys., 10, 4111-4131, https://doi.org/10.5194/acp-10-4111-2010, 2010.

Chhabra, P. S., Ng, N. L., Canagaratna, M. R., Corrigan, A. L., Russell, L. M., Worsnop, D. R., Flagan, R. C., and Seinfeld, J. H.: Elemental composition and oxidation of chamber organic aerosol, Atmos. Chem. Phys., 11, 8827-8845, https://doi.org/10.5194/acp-11-8827-2011, 2011.

Chung, S. H. and Seinfeld, J. H.: Global distribution and climate forcing of carbonaceous aerosols, J. Geophys. Res., 107, 4407, https://doi.org/10.1029/2001JD001397, 2002.

Clegg, S. L., Kleeman, M. J., Griffin, R. J., and Seinfeld, J. H.: Effects of uncertainties in the thermodynamic properties of aerosol components in an air quality model - Part 2: Predictions of the vapour pressures of organic compounds, Atmos. Chem. Phys., 8, 1087-1103, https://doi.org/10.5194/acp-8-1087-2008, 2008.

D’Anna, B., Wisthaler, A., Andreasen, Ø., Hansel, A., Hjorth, J., Jensen, N. R., Nielsen, C. J., Stenstrøm, Y., and Viidanoja, J.: Atmospheric chemistry of $\mathrm{C}_{3}-\mathrm{C}_{6}$ cycloalkanecarbaldehydes., J. Phys. Chem. A, 109, 5104-5118, https://doi.org/10.1021/jp044495g, 2005.

DeCarlo, P. F., Slowik, J. G., Worsnop, D. R., Davidovits, P., and Jimenez, J. L.: Particle morphology and density characterization by combined mobility and aerodynamic diameter measurements. Part 1: Theory, Aerosol Sci. Technol., 38, 1185-1205, https://doi.org/10.1080/02786826.2004.10399462, 2004.
DeCarlo, P. F., Kimmel, J. R., Trimborn, A., Northway, M. J., Jayne, J. T., Aiken, A. C., Gonin, M., Fuhrer, K., Horvath, T., Docherty, K. S., Worsnop, D. R., and Jimenez, J. L.: Field-deployable, high-resolution, time-of-flight aerosol mass spectrometer, Anal. Chem., 78, 8281-8289, https://doi.org/10.1021/ac061249n, 2006.

Donahue, N. M., Robinson, A. L., Stanier, C. O., and Pandis, S. N.: Coupled partitioning, dilution, and chemical aging of semivolatile organics, Environ. Sci. Technol., 40, 2635-2643, https://doi.org/10.1021/es052297c, 2006.

Donahue, N. M., Trump, E. R., Pierce, J. R., and Riipinen, I.: Theoretical constraints on pure vapor-pressure driven condensation of organics to ultrafine particles, Geophys. Res. Lett., 38, L16801, https://doi.org/10.1029/2011GL048115, 2011.

Donahue, N. M., Henry, K. M., Mentel, T. F., Kiendler-Scharr, A., Spindler, C., Bohn, B., Brauers, T., Dorn, H. P., Fuchs, H., Tillmann, R., Wahner, A., Saathoff, H., Naumann, K.-H., Möhler, O., Leisner, T., Müller, L., Reinnig, M.-C., Hoffmann, T., Salo, K., Hallquist, M., Frosch, M., Bilde, M., Tritscher, T., Barmet, P., Praplan, A. P., DeCarlo, P. F., Dommen, J., Prévôt, A. S. H., and Baltensperger, U.: Aging of biogenic secondary organic aerosol via gas-phase $\mathrm{OH}$ radical reactions, P. Natl. Acad. Sci. USA, 109, 13503-13508, https://doi.org/10.1073/pnas.1115186109, 2012.

Donahue, N. M., Ortega, I. K., Chuang, W., Riipinen, I., Riccobono, F., Schobesberger, S., Dommen, J., Baltensperger, U., Kulmala, M., Worsnop, D. R., and Vehkamaki, H.: How do organic vapors contribute to new-particle formation?, Faraday Discuss., 165, 91-104, https://doi.org/10.1039/c3fd00046j, 2013.

Draper, D. C., Farmer, D. K., Desyaterik, Y., and Fry, J. L.: A qualitative comparison of secondary organic aerosol yields and composition from ozonolysis of monoterpenes at varying concentrations of $\mathrm{NO}_{2}$, Atmos. Chem. Phys., 15, 12267-12281, https://doi.org/10.5194/acp-15-12267-2015, 2015.

Duncianu, M., David, M., Kartigueyane, S., Cirtog, M., Doussin, J.-F., and Picquet-Varrault, B.: Measurement of alkyl and multifunctional organic nitrates by proton-transfer-reaction mass spectrometry, Atmos. Meas. Tech., 10, 1445-1463, https://doi.org/10.5194/amt-10-1445-2017, 2017.

Eddingsaas, N. C., Loza, C. L., Yee, L. D., Chan, M., Schilling, K. A., Chhabra, P. S., Seinfeld, J. H., and Wennberg, P. O.: $\alpha$-pinene photooxidation under controlled chemical conditions - Part 2: SOA yield and composition in low- and high- $\mathrm{NO}_{x}$ environments, Atmos. Chem. Phys., 12, 7413-7427, https://doi.org/10.5194/acp-12-7413-2012, 2012.

Ehn, M., Thornton, J. A., Kleist, E., Sipilä, M., Junninen, H., Pullinen, I., Springer, M., Rubach, F., Tillmann, R., Lee, B., Lopez-Hilfiker, F., Andres, S., Acir, I.-H., Rissanen, M., Jokinen, T., Schobesberger, S., Kangasluoma, J., Kontkanen, J., Nieminen, T., Kurtén, T., Nielsen, L. B., Jørgensen, S., Kjaergaard, H. G., Canagaratna, M., Maso, M. D., Berndt, T., Petäjä, T., Wahner, A., Kerminen, V.-M., Kulmala, M., Worsnop, D. R., Wildt, J., and Mentel, T. F.: A large source of lowvolatility secondary organic aerosol, Nature, 506, 476-479, https://doi.org/10.1038/nature13032, 2014.

Fredenslund, A., Jones, R. L., and Prausnitz, J. M.: Group-contribution estimation of activity coefficients in nonideal liquid mixtures, AIChE J., 21, 1086-1099, https://doi.org/10.1002/aic.690210607, 1975. 
Graus, M., Müller, M., and Hansel, A.: High resolution PTRTOF: Quantification and formula confirmation of VOC in real time, J. Am. Soc. Mass Spectrom., 21, 1037-1044, https://doi.org/10.1016/j.jasms.2010.02.006, 2010.

Griffin, R. J., Cocker, D. R., Flagan, R. C., and Seinfeld, J. H.: Organic aerosol formation from the oxidation of biogenic hydrocarbons, J. Geophys. Res., 104, 3555-3567, https://doi.org/10.1029/1998JD100049, 1999a.

Griffin, R. J., Cocker, D. R., Seinfeld, J. H., and Dabdub, D.: Estimates of global atmospheric organic aerosol from oxidation of biogenic hydrocarbons, Geophys. Res. Lett., 26, 2721-2724, https://doi.org/10.1029/1999GL900476, 1999b.

Grimsrud, E. P., Westberg, H. H., and Rasmussen, R. A.: Atmospheric reactivity of monoterpene hydrocarbons, NO, photooxidation and ozonolysis, Int. J. Chem. Kinet. Symp., 1, 183-195, 1975.

Grosjean, D., Williams, E. L., and Grosjean, E.: Atmospheric chemistry of isoprene and of its carbonyl products, Environ. Sci. Technol., 27, 830-840, https://doi.org/10.1021/es00042a004, 1993.

Guenther, A., Hewitt, C. N., Erickson, D., Fall, R., Geron, C., Graedel, T., Harley, P., Klinger, L., Lerdau, M., McKay, W. A., Pierce, T., Scholes, B., Steinbrecher, R., Tallamraju, R., Taylor, J., and Zimmerman, P.: A global model of natural volatile organic compound emissions, J. Geophys. Res., 100, 8873-8892, https://doi.org/10.1029/94JD02950, 1995.

Guenther, A. B., Jiang, X., Heald, C. L., Sakulyanontvittaya, T., Duhl, T., Emmons, L. K., and Wang, X.: The Model of Emissions of Gases and Aerosols from Nature version 2.1 (MEGAN2.1): an extended and updated framework for modeling biogenic emissions, Geosci. Model Dev., 5, 1471-1492, https://doi.org/10.5194/gmd-5-1471-2012, 2012.

Hallquist, M., Wenger, J. C., Baltensperger, U., Rudich, Y., Simpson, D., Claeys, M., Dommen, J., Donahue, N. M., George, C., Goldstein, A. H., Hamilton, J. F., Herrmann, H., Hoffmann, T., Iinuma, Y., Jang, M., Jenkin, M. E., Jimenez, J. L., Kiendler-Scharr, A., Maenhaut, W., McFiggans, G., Mentel, Th. F., Monod, A., Prévôt, A. S. H., Seinfeld, J. H., Surratt, J. D., Szmigielski, R., and Wildt, J.: The formation, properties and impact of secondary organic aerosol: current and emerging issues, Atmos. Chem. Phys., 9, 5155-5236, https://doi.org/10.5194/acp9-5155-2009, 2009.

He, C., Murray, F., and Lyons, T.: Monoterpene and isoprene emissions from 15 Eucalyptus species in Australia, Atmos. Environ., 34, 645-655, https://doi.org/10.1016/S1352-2310(99)00219-8, 2000.

Heald, C. L., Kroll, J. H., Jimenez, J. L., Docherty, K. S., Decarlo, P. F., Aiken, A. C., Chen, Q., Martin, S. T., Farmer, D. K., and Artaxo, P.: A simplified description of the evolution of organic aerosol composition in the atmosphere, Geophys. Res. Lett., 37, L08803, https://doi.org/10.1029/2010GL042737, 2010.

Heaton, K. J., Sleighter, R. L., Hatcher, P. G., Hall, W. A., and Johnston, M. V.: Composition domains in monoterpene secondary organic aerosol, Environ. Sci. Technol., 43, 7797-7802, https://doi.org/10.1021/es901214p, 2009.

Henze, D. K. and Seinfeld, J. H.: Global secondary organic aerosol from isoprene oxidation, Geophys. Res. Lett., 33, L09812, https://doi.org/10.1029/2006GL025976, 2006.

Herrmann, F., Winterhalter, R., Moortgat, G. K., and Williams, J.: Hydroxyl radical $(\mathrm{OH})$ yields from the ozonolysis of both double bonds for five monoterpenes, Atmos. Environ., 44, 3458-3464, https://doi.org/10.1016/j.atmosenv.2010.05.011, 2010.

Hoffmann, T., Odum, J. R., Bowman, F., Collins, D., Klockow, D., Flagan, R. C., and Seinfeld, J. H.: Formation of organic aerosols from the oxidation of biogenic hydrocarbons, J. Atmos. Chem., 26, 189-222, https://doi.org/10.1023/A:1005734301837, 1997.

Huffman, J. A., Jayne, J. T., Drewnick, F., Aiken, A. C., Onasch, T., Worsnop, D. R., and Jimenez, J. L.: Design, modeling, optimization, and experimental tests of a particle beam width probe for the aerodyne aerosol mass spectrometer, Aerosol Sci. Technol., 39 1143-1163, https://doi.org/10.1080/02786820500423782, 2005.

Jathar, S. H., Cappa, C. D., Wexler, A. S., Seinfeld, J. H., and Kleeman, M. J.: Simulating secondary organic aerosol in a regional air quality model using the statistical oxidation model - Part 1: Assessing the influence of constrained multi-generational ageing, Atmos. Chem. Phys., 16, 2309-2322, https://doi.org/10.5194/acp-16-2309-2016, 2016.

Jayne, J. T., Leard, D. C., Zhang, X., Davidovits, P., Smith, K. A., Kolb, C. E., and Worsnop, D. R.: Development of an aerosol mass spectrometer for size and composition analysis of submicron particles, Aerosol Sci. Technol., 33, 49-70, https://doi.org/10.1080/027868200410840, 2000.

Jenkin, M. E.: Modelling the formation and composition of secondary organic aerosol from $\alpha$ - and $\beta$-pinene ozonolysis using MCM v3, Atmos. Chem. Phys., 4, 1741-1757, https://doi.org/10.5194/acp-4-1741-2004, 2004.

Jenkin, M. E., Saunders, S. M., and Pilling, M. J.: The tropospheric degradation of volatile organic compounds: A protocol for mechanism development, Atmos. Environ., 31, 81-104, https://doi.org/10.1016/S1352-2310(96)00105-7, 1997.

Johnson, D. and Marston, G.: The gas-phase ozonolysis of unsaturated volatile organic compounds in the troposphere., Chem. Soc. Rev., 37, 699-716, https://doi.org/10.1039/b704260b, 2008.

Jokinen, T., Berndt, T., Makkonen, R., Kerminen, V.-M., Junninen, H., Paasonen, P., Stratmann, F., Herrmann, H., Guenther, A. B., Worsnop, D. R., Kulmala, M., Ehn, M., and Sipilä, M.: Production of extremely low volatile organic compounds from biogenic emissions: Measured yields and atmospheric implications, P. Natl. Acad. Sci. USA, 112, 7123-7128, https://doi.org/10.1073/pnas.1423977112, 2015.

Jordan, A., Haidacher, S., Hanel, G., Hartungen, E., Märk, L., Seehauser, H., Schottkowsky, R., Sulzer, P., and Märk, T. D.: A high resolution and high sensitivity proton-transfer-reaction time-offlight mass spectrometer (PTR-TOF-MS), Int. J. Mass Spectrom., 286, 122-128, https://doi.org/10.1016/j.ijms.2009.07.005, 2009.

Katrib, Y., Martin, S. T., Rudich, Y., Davidovits, P., Jayne, J. T., and Worsnop, D. R.: Density changes of aerosol particles as a result of chemical reaction, Atmos. Chem. Phys., 5, 275-291, https://doi.org/10.5194/acp-5-275-2005, 2005.

Keywood, M. D., Kroll, J. H., Varutbangkul, V., Bahreini, R., Flagan, R. C., and Seinfeld, J. H.: Secondary organic aerosol formation from cyclohexene ozonolysis: Effect of $\mathrm{OH}$ scavenger and the role of radical chemistry, Environ. Sci. Technol., 38, 33433350, https://doi.org/10.1021/es049725j, 2004.

Kirchstetter, T. W., Corrigan, C. E., and Novakov, T.: Laboratory and field investigation of the adsorption of gaseous organic compounds onto quartz filters, Atmos. Environ., 35, 1663-1671, https://doi.org/10.1016/S1352-2310(00)00448-9, 2001. 
Kostenidou, E., Pathak, R. K., and Pandis, S. N.: An algorithm for the calculation of secondary organic aerosol density combining AMS and SMPS data, Aerosol Sci. Technol., 41, 1002-1010, https://doi.org/10.1080/02786820701666270, 2007.

Krechmer, J. E., Pagonis, D., Ziemann, P. J., and Jimenez, J. L.: Quantification of Gas-Wall Partitioning in Teflon Environmental Chambers Using Rapid Bursts of Low-Volatility Oxidized Species Generated in Situ, Environ. Sci. Technol., 50, 57575765, https://doi.org/10.1021/acs.est.6b00606, 2016.

Kroll, J. H., Donahue, N. M., Jimenez, J. L., Kessler, S. H., Canagaratna, M. R., Wilson, K. R., Altieri, K. E., Mazzoleni, L. R., Wozniak, A. S., Bluhm, H., Mysak, E. R., Smith, J. D., Kolb, C. E., and Worsnop, D. R.: Carbon oxidation state as a metric for describing the chemistry of atmospheric organic aerosol, Nat. Chem., 3, 133-139, https://doi.org/10.1038/nchem.948, 2011.

Kuwata, M., Zorn, S. R., and Martin, S. T.: Using elemental ratios to predict the density of organic material composed of carbon, hydrogen, and oxygen, Environ. Sci. Technol., 46, 787-794, https://doi.org/10.1021/es202525q, 2012.

La, Y. S., Camredon, M., Ziemann, P. J., Valorso, R., Matsunaga, A., Lannuque, V., Lee-Taylor, J., Hodzic, A., Madronich, S., and Aumont, B.: Impact of chamber wall loss of gaseous organic compounds on secondary organic aerosol formation: explicit modeling of SOA formation from alkane and alkene oxidation, Atmos. Chem. Phys., 16, 1417-1431, https://doi.org/10.5194/acp16-1417-2016, 2016.

Lathière, J., Hauglustaine, D. A., Friend, A. D., De NobletDucoudré, N., Viovy, N., and Folberth, G. A.: Impact of climate variability and land use changes on global biogenic volatile organic compound emissions, Atmos. Chem. Phys., 6, 2129-2146, https://doi.org/10.5194/acp-6-2129-2006, 2006.

Lee, A., Goldstein, A. H., Keywood, M. D., Gao, S., Varutbangkul, V., Bahreini, R., Ng, N. L., Flagan, R. C., and Seinfeld, J. H.: Gas-phase products and secondary aerosol yields from the ozonolysis of ten different terpenes, J. Geophys. Res., 111, D07302, https://doi.org/10.1029/2006JD007050, 2006.

Lee, S.-H., Young, L.-H., Benson, D. R., Suni, T., Kulmala, M., Junninen, H., Campos, T. L., Rogers, D. C., and Jensen, J.: Observations of nighttime new particle formation in the troposphere, J. Geophys. Res., 113, D10210, https://doi.org/10.1029/2007JD009351, 2008.

Leungsakul, S., Jaoui, M., and Kamens, R. M.: Kinetic mechanism for predicting secondary organic aerosol formation from the reaction of d-limonene with ozone, Environ. Sci. Technol., 39, 9583-9594, https://doi.org/10.1021/es0492687, 2005.

Li, H., Madden, J. L., and Potts, B. M.: Variation in volatile leaf oils of the tasmanian Eucalyptus species - 1. Subgenus Monocalyptus, Biochem. Syst. Ecol., 23, 299-318, https://doi.org/10.1016/0305-1978(95)97455-6, 1995.

Liu, T., Wang, X., Deng, W., Hu, Q., Ding, X., Zhang, Y., He, Q., Zhang, Z., Lü, S., Bi, X., Chen, J., and Yu, J.: Secondary organic aerosol formation from photochemical aging of lightduty gasoline vehicle exhausts in a smog chamber, Atmos. Chem. Phys., 15, 9049-9062, https://doi.org/10.5194/acp-159049-2015, 2015.

Ma, Y., Willcox, T. R., Russell, A. T., and Marston, G.: Pinic and pinonic acid formation in the reaction of ozone with $\alpha$-pinene., Chem. Commun., 13, 1328-1330, https://doi.org/10.1039/b617130c, 2007.
Mackenzie-Rae, F. A., Karton, A., and Saunders, S. M.: Computational investigation into the gas-phase ozonolysis of the conjugated monoterpene $\alpha$-phellandrene, Phys. Chem. Chem. Phys., 18, 27991-28002, https://doi.org/10.1039/C6CP04695A, 2016.

Maghsoodlou, M. T., Kazemipoor, N., Valizadeh, J., Falak Nezhad Seifi, M., and Rahneshan, N.: Essential oil composition of Eucalyptus microtheca and Eucalyptus viminalis, Avicenna J. Phytomedicine, 5, 540-552, 2015.

Maisey, S. J., Saunders, S. M., West, N., and Franklin, P. J.: An extended baseline examination of indoor VOCs in a city of low ambient pollution: Perth, Western Australia, Atmos. Environ., 81, 546-553, https://doi.org/10.1016/j.atmosenv.2013.09.008, 2013.

Maleknia, S. D., Bell, T. L., and Adams, M. A.: Eucalypt smoke and wildfires: Temperature dependent emissions of biogenic volatile organic compounds, Int. J. Mass Spectrom., 279, 126133, https://doi.org/10.1016/j.ijms.2008.10.027, 2009.

Matsunaga, A. and Ziemann, P. J.: Gas-Wall Partitioning of Organic Compounds in a Teflon Film Chamber and Potential Effects on Reaction Product and Aerosol Yield Measurements, Aerosol Sci. Technol., 44, 881-892, https://doi.org/10.1080/02786826.2010.501044, 2010.

Matthew, B. M., Middlebrook, A. M., and Onasch, T. B.: Collection efficiencies in an aerodyne aerosol mass spectrometer as a function of particle phase for laboratory generated aerosols, Aerosol Sci. Technol., 42, 884-898, https://doi.org/10.1080/02786820802356797, 2008.

Misztal, P. K., Heal, M. R., Nemitz, E., and Cape, J. N.: Development of PTR-MS selectivity for structural isomers: Monoterpenes as a case study, Int. J. Mass Spectrom., 310, 10-19, https://doi.org/10.1016/j.ijms.2011.11.001, 2012.

Moller, B., Rarey, J., and Ramjugernath, D.: Estimation of the vapour pressure of non-electrolyte organic compounds via group contributions and group interactions, J. Mol. Liq., 143, 52-63, https://doi.org/10.1016/j.molliq.2008.04.020, 2008.

Müller, M., Graus, M., Wisthaler, A., Hansel, A., Metzger, A., Dommen, J., and Baltensperger, U.: Analysis of high mass resolution PTR-TOF mass spectra from 1,3,5-trimethylbenzene (TMB) environmental chamber experiments, Atmos. Chem. Phys., 12, 829-843, https://doi.org/10.5194/acp-12-829-2012, 2012.

Müller, M., Mikoviny, T., Jud, W., D’Anna, B., and Wisthaler, A.: A new software tool for the analysis of high resolution PTRTOF mass spectra, Chemom. Intell. Lab. Syst., 127, 158-165, https://doi.org/10.1016/j.chemolab.2013.06.011, 2013.

Myburg, A. A., Grattapaglia, D., Tuskan, G. A., Hellsten, U., Hayes, R. D., Grimwood, J., Jenkins, J., Lindquist, E., Tice, H., Bauer, D., Goodstein, D. M., Dubchak, I., Poliakov, A., Mizrachi, E., Kullan, A. R. K., Hussey, S. G., Pinard, D., van der Merwe, K., Singh, P., Van Jaarsveld, I., Silva-Junior, O. B., Togawa, R. C., Pappas, M. R., Faria, D. A., Sansaloni, C. P., Petroli, C. D., Yang, X., Ranjan, P., Tschaplinski, T. J., Ye, C.-Y., Li, T., Sterck, L., Vanneste, K., Murat, F., Soler, M. M., Clemente, H. S. H. S., Saidi, N., Cassan-Wang, H., Dunand, C., Hefer, C. A., Bornberg-Bauer, E., Kersting, A. R., Vining, K., Amarasinghe, V., Ranik, M., Naithani, S., Elser, J., Boyd, A. E., Liston, A., Spatafora, J. W., Dharmwardhana, P., Raja, R., Sullivan, C., Romanel, E., Alves-Ferreira, M., Lheim, C. K., Foley, W., Carocha, V., Paiva, J., Kudrna, D., Brommonschenkel, S. H., Pasquali, G., Byrne, M., Rigault, P., Tibbits, J., Spokevicius, A., Jones, 
R. C., Steane, D. A., Vaillancourt, R. E. R. E., Potts, B. M., Joubert, F., Barry, K., Pappas Jr., G. J., Strauss, S. H., Jaiswal, P., Grima-Pettenati, J., Salse, J. J., Van de Peer, Y., Rokhsar, D. S., Schmutz, J., Külheim, C., Foley, W., Carocha, V., Paiva, J., Kudrna, D., Brommonschenkel, S. H., Pasquali, G., Byrne, M., Rigault, P., Tibbits, J., Spokevicius, A., Jones, R. C., Steane, D. A., Vaillancourt, R. E. R. E., Potts, B. M., Joubert, F., Barry, K., Pappas, G. J., Strauss, S. H., Jaiswal, P., Grima-Pettenati, J., Salse, J. J., Van de Peer, Y., Rokhsar, D. S., and Schmutz, J.: The genome of Eucalyptus grandis, Nature, 510, 356-362, https://doi.org/10.1038/nature13308, 2014.

Nannoolal, Y., Rarey, J., Ramjugernath, D., and Cordes, W.: Estimation of pure component properties: Part 1. Estimation of the normal boiling point of non-electrolyte organic compounds via group contributions and group interactions, Fluid Phase Equilib., 226, 45-63, https://doi.org/10.1016/j.fluid.2004.09.001, 2004.

Ng, N. L., Kroll, J. H., Keywood, M. D., Bahreini, R., Varutbangkul, V., Flagan, R. C., and Seinfeld, J. H.: Contribution of firstversus second-generation products to secondary organic aerosols formed in the oxidation of biogenic hydrocarbons, Environ. Sci. Technol., 40, 2283-2297, https://doi.org/10.1021/es052269u, 2006

Ng, N. L., Chhabra, P. S., Chan, A. W. H., Surratt, J. D., Kroll, J. H., Kwan, A. J., McCabe, D. C., Wennberg, P. O., Sorooshian, A., Murphy, S. M., Dalleska, N. F., Flagan, R. C., and Seinfeld, J. H.: Effect of $\mathrm{NO}_{x}$ level on secondary organic aerosol (SOA) formation from the photooxidation of terpenes, Atmos. Chem. Phys., 7, 5159-5174, https://doi.org/10.5194/acp-7-5159-2007, 2007.

Nguyen, T. L., Peeters, J., and Vereecken, L.: Theoretical study of the gas-phase ozonolysis of $\beta$-pinene $\left(\mathrm{C}_{10} \mathrm{H}_{16}\right)$, Phys. Chem. Chem. Phys., 11, 5643-5656, https://doi.org/10.1039/B822984h, 2009.

Odum, J. R., Hoffmann, T., Bowman, F., Collins, D., Flagan, R. C., and Seinfeld, J. H.: Gas/particle partitioning and secondary organic aerosol yields, Environ. Sci. Technol., 30, 2580-2585, https://doi.org/10.1021/es950943+, 1996.

O'Meara, S., Booth, A. M., Barley, M. H., Topping, D., and McFiggans, G.: An assessment of vapour pressure estimation methods., Phys. Chem. Chem. Phys., 16, 19453-19469, https://doi.org/10.1039/c4cp00857j, 2014.

Ortega, I. K., Suni, T., Grönholm, T., Boy, M., Hakola, H., Hellén, H., Valmari, T., Arvela, H., Vehkamäki, H., and Kulmala, M.: Is eucalyptol the cause of nocturnal events observed in Australia?, Boreal Environ. Res., 14, 606-615, 2009.

Ortega, I. K., Suni, T., Boy, M., Grönholm, T., Manninen, H. E., Nieminen, T., Ehn, M., Junninen, H., Hakola, H., Hellén, H., Valmari, T., Arvela, H., Zegelin, S., Hughes, D., Kitchen, M., Cleugh, H., Worsnop, D. R., Kulmala, M., and Kerminen, V.-M.: New insights into nocturnal nucleation, Atmos. Chem. Phys., 12, 4297-4312, https://doi.org/10.5194/acp-12-4297-2012, 2012.

Pankow, J. F.: An absorption model of gas/particle partitioning of organic compounds in the atmosphere, Atmos. Environ., 28, 185-188, https://doi.org/10.1016/1352-2310(94)90093-0, 1994.

Pankow, J. F. and Asher, W. E.: SIMPOL.1: a simple group contribution method for predicting vapor pressures and enthalpies of vaporization of multifunctional organic compounds, Atmos. Chem. Phys., 8, 2773-2796, https://doi.org/10.5194/acp-8-27732008, 2008.
Pathak, R. K., Stanier, C. O., Donahue, N. M., and Pandis, S. N.: Ozonolysis of $\alpha$-pinene at atmospherically relevant concentrations: Temperature dependence of aerosol mass fractions (yields), J. Geophys. Res., 112, D03201, https://doi.org/10.1029/2006JD007436, 2007.

Paulson, S. E., Flagan, R. C., and Seinfeld, J. H.: Atmospheric photooxidation of isoprene part II. The ozoneisoprene reaction, Int. J. Chem. Kinet., 24, 103-125, https://doi.org/10.1002/kin.550240110, 1992.

Pavlova, L. V., Platonov, I. A., Nikitchenko, N. V., and Novikova, E. A.: Evaluation of the efficiency of volatile organic compounds extraction from Eucalyptus viminalis (Eucalypti viminalis Labill) using subcritical extractants, Russ. J. Phys. Chem. B, 9, 1109-1115, https://doi.org/10.1134/S1990793115080084, 2015.

Perraud, V., Bruns, E. A., Ezell, M. J., Johnson, S. N., Yu, Y., Alexander, M. L., Zelenyuk, A., Imre, D., Chang, W. L., Dabdub, D., Pankow, J. F., and Finlayson-Pitts, B. J.: Nonequilibrium atmospheric secondary organic aerosol formation and growth., P. Natl. Acad. Sci. USA, 109, 2836-2841, https://doi.org/10.1073/pnas.1119909109, 2012.

Pierce, J. R., Riipinen, I., Kulmala, M., Ehn, M., Petäjä, T., Junninen, H., Worsnop, D. R., and Donahue, N. M.: Quantification of the volatility of secondary organic compounds in ultrafine particles during nucleation events, Atmos. Chem. Phys., 11, 90199036, https://doi.org/10.5194/acp-11-9019-2011, 2011.

Presto, A. A., Huff Hartz, K. E., and Donahue, N. M.: Secondary organic aerosol production from terpene ozonolysis. 2. Effect of $\mathrm{NO}_{x}$ concentration, Environ. Sci. Technol., 39, 7046-7054, https://doi.org/10.1021/es050400s, 2005.

Pye, H. O. T., Chan, A. W. H., Barkley, M. P., and Seinfeld, J. H.: Global modeling of organic aerosol: the importance of reactive nitrogen $\left(\mathrm{NO}_{x}\right.$ and $\left.\mathrm{NO}_{3}\right)$, Atmos. Chem. Phys., 10, 1126111276, https://doi.org/10.5194/acp-10-11261-2010, 2010.

Reissell, A., Harry, C., Aschmann, S. M., Atkinson, R., and Arey, J.: Formation of acetone from the $\mathrm{OH}$ radical- and $\mathrm{O}_{3}$-initiated reactions of a series of monoterpenes, J. Geophys. Res., 104, 13869 13879, https://doi.org/10.1029/1999JD900198, 1999.

Rickard, A. R., Johnson, D., McGill, C. D., and Marston, G.: OH yields in the gas-phase reactions of ozone with alkenes, J. Phys. Chem. A, 103, 7656-7664, https://doi.org/10.1021/jp9916992, 1999.

Saathoff, H., Naumann, K.-H., Möhler, O., Jonsson, Å. M., Hallquist, M., Kiendler-Scharr, A., Mentel, Th. F., Tillmann, R., and Schurath, U.: Temperature dependence of yields of secondary organic aerosols from the ozonolysis of a-pinene and limonene, Atmos. Chem. Phys., 9, 1551-1577, https://doi.org/10.5194/acp9-1551-2009, 2009.

Sadezky, A., Chaimbault, P., Mellouki, A., Römpp, A., Winterhalter, R., Le Bras, G., and Moortgat, G. K.: Formation of secondary organic aerosol and oligomers from the ozonolysis of enol ethers, Atmos. Chem. Phys., 6, 5009-5024, https://doi.org/10.5194/acp6-5009-2006, 2006.

Sadezky, A., Winterhalter, R., Kanawati, B., Römpp, A., Spengler, B., Mellouki, A., Le Bras, G., Chaimbault, P., and Moortgat, G. K.: Oligomer formation during gas-phase ozonolysis of small alkenes and enol ethers: new evidence for the central role of the Criegee Intermediate as oligomer chain unit, Atmos. Chem. Phys., 8, 2667-2699, https://doi.org/10.5194/acp-8-2667-2008, 2008. 
Sakamoto, Y., Inomata, S., and Hirokawa, J.: Oligomerization reaction of the Criegee intermediate leads to secondary organic aerosol formation in ethylene ozonolysis, J. Phys. Chem. A, 117, 12912-12921, https://doi.org/10.1021/jp408672m, 2013.

Saunders, S. M., Jenkin, M. E., Derwent, R. G., and Pilling, M. J.: Protocol for the development of the Master Chemical Mechanism, MCM v3 (Part A): tropospheric degradation of nonaromatic volatile organic compounds, Atmos. Chem. Phys., 3, 161-180, https://doi.org/10.5194/acp-3-161-2003, 2003.

Schurgers, G., Arneth, A., Holzinger, R., and Goldstein, A. H.: Process-based modelling of biogenic monoterpene emissions combining production and release from storage, Atmos. Chem. Phys., 9, 3409-3423, https://doi.org/10.5194/acp-9-3409-2009, 2009.

Shilling, J. E., Chen, Q., King, S. M., Rosenoern, T., Kroll, J. H., Worsnop, D. R., McKinney, K. A., and Martin, S. T.: Particle mass yield in secondary organic aerosol formed by the dark ozonolysis of a-pinene, Atmos. Chem. Phys., 8, 2073-2088, https://doi.org/10.5194/acp-8-2073-2008, 2008.

Shilling, J. E., Chen, Q., King, S. M., Rosenoern, T., Kroll, J. H., Worsnop, D. R., DeCarlo, P. F., Aiken, A. C., Sueper, D., Jimenez, J. L., and Martin, S. T.: Loading-dependent elemental composition of a-pinene SOA particles, Atmos. Chem. Phys., 9, 771-782, https://doi.org/10.5194/acp-9-771-2009, 2009.

Shu, Y. and Atkinson, R.: Rate constants for the gas-phase reactions of $\mathrm{O}_{3}$ with a series of terpenes and $\mathrm{OH}$ radical formation from the $\mathrm{O}_{3}$ reactions with sesquiterpenes at $296 \pm 2 \mathrm{~K}$, Int. J. Chem. Kinet., 26, 1193-1205, https://doi.org/10.1002/kin.550261207, 1994.

Sindelarova, K., Granier, C., Bouarar, I., Guenther, A., Tilmes, S., Stavrakou, T., Müller, J.-F., Kuhn, U., Stefani, P., and Knorr, W.: Global data set of biogenic VOC emissions calculated by the MEGAN model over the last 30 years, Atmos. Chem. Phys., 14, 9317-9341, https://doi.org/10.5194/acp-14-9317-2014, 2014.

Slowik, J. G., Stainken, K., Davidovits, P., Williams, L. R., Jayne, J. T., Kolb, C. E., Worsnop, D. R., Rudich, Y., DeCarlo, P. F., and Jimenez, J. L.: Particle morphology and density characterization by combined mobility and aerodynamic diameter measurements. Part 2: Application to combustion-generated soot aerosols as a function of fuel equivalence ratio, Aerosol Sci. Technol., 38, 1206-1222, https://doi.org/10.1080/02786826.2004.10399462, 2004.

Smith, D. and Španěl, P.: Selected ion flow tube mass spectrometry (SIFT-MS) for on-line trace gas analysis, Mass Spectrom. Rev., 24, 661-700, https://doi.org/10.1002/mas.20033, 2005.

Španěl, P. and Smith, D.: SIFT studies of the reactions of $\mathrm{H}_{3} \mathrm{O}^{+}$, $\mathrm{NO}^{+}$and $\mathrm{O}_{2}^{+}$with a series of volatile carboxylic acids and esters, Int. J. Mass Spectrom. Ion Process., 172, 137-147, https://doi.org/10.1016/S0168-1176(97)00246-2, 1998.

Španěl, P., Ji, Y., and Smith, D.: SIFT studies of the reactions of $\mathrm{H}_{3} \mathrm{O}^{+}, \mathrm{NO}^{+}$and $\mathrm{O}_{2}^{+}$with a series of aldehydes and ketones, Int. J. Mass Spectrom. Ion Process., 165/166, 25-37, https://doi.org/10.1016/S0168-1176(97)00166-3, 1997.

Stanier, C. O., Donahue, N., and Pandis, S. N.: Parameterization of secondary organic aerosol mass fractions from smog chamber data, Atmos. Environ., 42, 2276-2299, https://doi.org/10.1016/j.atmosenv.2007.12.042, 2008.

Stranger, M.: Emissions, exposure patterns and health effects of consumer products in the EU (EPHECT), Presented in part at Green Week 2013, Brussels, available at: http://ec.europa. eu/environment/archives/greenweek2013 (last access: 5 January 2017), 2013.

Suni, T., Kulmala, M., Hirsikko, A., Bergman, T., Laakso, L., Aalto, P. P., Leuning, R., Cleugh, H., Zegelin, S., Hughes, D., van Gorsel, E., Kitchen, M., Vana, M., Hõrrak, U., Mirme, S., Mirme, A., Sevanto, S., Twining, J., and Tadros, C.: Formation and characteristics of ions and charged aerosol particles in a native Australian Eucalypt forest, Atmos. Chem. Phys., 8, 129-139, https://doi.org/10.5194/acp-8-129-2008, 2008.

Tani, A.: Fragmentation and reaction rate constants of terpenoids determined by proton transfer reaction-mass spectrometry, Environ. Control Biol., 51, 23-29, https://doi.org/10.2525/ecb.51.23, 2013.

Tsigaridis, K. and Kanakidou, M.: Global modelling of secondary organic aerosol in the troposphere: a sensitivity analysis, Atmos. Chem. Phys., 3, 1849-1869, https://doi.org/10.5194/acp-3-18492003, 2003.

Turpin, B. J., Saxena, P., and Andrews, E.: Measuring and simulating particulate organics in the atmosphere: Problems and prospects, Atmos. Environ., 34, 2983-3013, https://doi.org/10.1016/S1352-2310(99)00501-4, 2000.

Vereecken, L., Glowacki, D. R., and Pilling, M. J.: Theoretical Chemical Kinetics in Tropospheric Chemistry: Methodologies and Applications, Chem. Rev., 115, 4063-4114, https://doi.org/10.1021/cr500488p, 2015.

von Hessberg, C., von Hessberg, P., Pöschl, U., Bilde, M., Nielsen, O. J., and Moortgat, G. K.: Temperature and humidity dependence of secondary organic aerosol yield from the ozonolysis of $\beta$-pinene, Atmos. Chem. Phys., 9, 3583-3599, https://doi.org/10.5194/acp-9-3583-2009, 2009.

Walser, M. L., Desyaterik, Y., Laskin, J., Laskin, A., and Nizkorodov, S. A.: High-resolution mass spectrometric analysis of secondary organic aerosol produced by ozonation of limonene., Phys. Chem. Chem. Phys., 10, 1009-1022, https://doi.org/10.1039/B712620D, 2008.

Wang, M., Yao, L., Zheng, J., Wang, X., Chen, J., Yang, X., Worsnop, D. R., Donahue, N. M., and Wang, L.: Reactions of Atmospheric Particulate Stabilized Criegee Intermediates Lead to High-Molecular-Weight Aerosol Components, Environ. Sci. Technol., 50, 5702-5710, https://doi.org/10.1021/acs.est.6b02114, 2016.

Wang, S. C. and Flagan, R. C.: Scanning electrical mobility spectrometer, Aerosol Sci. Technol., 13, 230-240, https://doi.org/10.1016/0021-8502(89)90868-9, 1990.

Wang, X., Liu, T., Bernard, F., Ding, X., Wen, S., Zhang, Y., Zhang, Z., He, Q., Lü, S., Chen, J., Saunders, S., and Yu, J.: Design and characterization of a smog chamber for studying gas-phase chemical mechanisms and aerosol formation, Atmos. Meas. Tech., 7, 301-313, https://doi.org/10.5194/amt-7301-2014, 2014.

Wiedensohler, A., Birmili, W., Nowak, A., Sonntag, A., Weinhold, K., Merkel, M., Wehner, B., Tuch, T., Pfeifer, S., Fiebig, M., Fjäraa, A. M., Asmi, E., Sellegri, K., Depuy, R., Venzac, H., Villani, P., Laj, P., Aalto, P., Ogren, J. A., Swietlicki, E., Williams, P., Roldin, P., Quincey, P., Hüglin, C., Fierz-Schmidhauser, R., Gysel, M., Weingartner, E., Riccobono, F., Santos, S., Grüning, C., Faloon, K., Beddows, D., Harrison, R., Monahan, C., Jennings, S. G., O’Dowd, C. D., Marinoni, A., Horn, H.-G., 
Keck, L., Jiang, J., Scheckman, J., McMurry, P. H., Deng, Z., Zhao, C. S., Moerman, M., Henzing, B., de Leeuw, G., Löschau, G., and Bastian, S.: Mobility particle size spectrometers: harmonization of technical standards and data structure to facilitate high quality long-term observations of atmospheric particle number size distributions, Atmos. Meas. Tech., 5, 657-685, https://doi.org/10.5194/amt-5-657-2012, 2012.

Winterhalter, R., Herrmann, F., Kanawati, B., Nguyen, T. L., Peeters, J., Vereecken, L., and Moortgat, G. K.: The gasphase ozonolysis of $\beta$-caryophyllene $\left(\mathrm{C}_{15} \mathrm{H}_{24}\right)$. Part I: an experimental study, Phys. Chem. Chem. Phys., 11, 4152-4172, https://doi.org/10.1039/b817824k, 2009.

Yeh, G. K. and Ziemann, P. J.: Gas-Wall Partitioning of Oxygenated Organic Compounds: Measurements, StructureActivity Relationships, and Correlation with Gas Chromatographic Retention Factor, Aerosol Sci. Technol., 49, 727-738, https://doi.org/10.1080/02786826.2015.1068427, 2015.
Zhang, D. and Zhang, R.: Ozonolysis of $\alpha$-pinene and $\beta$ pinene: Kinetics and mechanism, J. Chem. Phys., 122, 114308, https://doi.org/10.1063/1.1862616, 2005.

Zhang, X., Cappa, C. D., Jathar, S. H., McVay, R. C., Ensberg, J. J., Kleeman, M. J., and Seinfeld, J. H.: Influence of vapor wall loss in laboratory chambers on yields of secondary organic aerosol, P. Natl. Acad. Sci. USA, 111, 5802-5807, https://doi.org/10.1073/pnas.1404727111, 2014.

Zhao, D. F., Kaminski, M., Schlag, P., Fuchs, H., Acir, I.-H., Bohn, B., Häseler, R., Kiendler-Scharr, A., Rohrer, F., Tillmann, R., Wang, M. J., Wegener, R., Wildt, J., Wahner, A., and Mentel, Th. F.: Secondary organic aerosol formation from hydroxyl radical oxidation and ozonolysis of monoterpenes, Atmos. Chem. Phys., 15, 991-1012, https://doi.org/10.5194/acp-15-991-2015, 2015. 